The Phonetics and Phonology of Semitic Pharyngeals ${ }^{1}$

John J. McCarthy

University of Massachusetts, Amherst

\title{
X.1 Introduction
}

An adequate theory of phonological distinctive features must meet four criteria: (i) it must have a relatively consistent and direct relation to the phonetic properties of speech sounds; (ii) it must be able to describe all and only the distinctions made by the sound systems of any of the world's languages; (iii) it must be able to characterize all and only the natural classes of sounds that recur in the phonological phenomena of different languages; and (iv) it must correctly characterize the subgrouping of features by recurrent phonological phenomena. The third criterion is the most important one and probably the hardest to achieve. The fourth has assumed greater importance in the last five years or so in the context of work on feature geometry (Clements 1985, Sagey 1986, and others).

The Semitic languages have many consonants produced with a primary constriction in the posterior regions of the vocal tract. Traditional grammars refer to these consonants as "gutturals". Standard Arabic and most modern Arabic dialects have retained the full set of gutturals usually reconstructed for Proto-Semitic: laryngeals $\underline{?}$ and $\underline{h} ;$ pharyngeals $\underline{\hbar}$ and $\underline{\mathbf{S}} ;$ and uvulars $\mathbf{X}$ and $\underline{\mathbf{b}}$. Other Semitic languages, as well as several other branches of the larger Afro-asiatic family, have similar or smaller inventories of gutturals.

The phonology of the various Semitic languages provides a remarkable range of evidence that the gutturals are treated as a natural class by phonological rules. This can be shown through independent developments in the various languages at different historical periods and in different areas of the phonology. Reference to the guttural class is not limited to just underlying or just surface level, but rather pervades the phonological structure of these languages. From these observations, it follows that the 
gutturals must constitute a robust natural class that is directly represented within distinctive feature theory.

By detailed examination of the acoustic and articulatory properties of the semitic gutturals, I show that they constitute a class in terms of a traditional means of classifying consonants, point of articulation. Specifically, I argue that the natural class of gutturals is defined by their place of articulation, [pharyngeal]. The [pharyngeal] consonants are produced with a constriction anywhere in the entire region that encompasses the larynx through the oropharynx, a constriction locus that correlates acoustically with a relatively high Fl. I then go on to relate this idea to a proposal by Perkell (1980) that distinctive features are orosensory $\underline{\underline{\text { targets}}}$, and I suggest that the difference between [pharyngeal] and other place-of-articulation features lies in the varying distribution of sensory feed-back mechanisms in different regions of the vocal tract. Ultimately, the thesis I develop is not unlike the earliest classification of these sounds by the Arab grammarian Sibawaihi. In his terms, the gutturals are all "throat consonants", produced at "the back of the throat" (laryngeals), "the middle of the throat" (pharyngeals), and "the part of the throat nearest the mouth" (uvulars). It is also quite similar to Hayward and Hayward's (1989) independent proposal that there is a feature [guttural] characterizing a "zone" rather than a place of articulation, justified mostly on the basis of Cushitic rather than semitic evidence.

Having established the properties of the feature [pharyngeal] and the evidence for it, I then turn to the issue of how it relates to other distinctive features. First, I sketch some of the phonetic and phonological properties of the emphatics, the coronal and uvular pharyngealized consonants, contrasting them with the gutturals. Second, I briefly indicate how [pharyngeal] fits into a model of feature geometry, a subject examined in depth in McCarthy (forthcoming). Third, I return to take a closer look at the laryngeal consonants, which are not always members of the guttural class. 
There are also very rich systems of uvular, pharyngeal, and laryngeal consonants in the Northwest Caucasian languages as documented by Catford (1983) and Colarusso (1988). Unfortunately, relatively little is known about the phonological systems of these languages apart from phoneme lists, whereas virtually all of the conclusions about semitic are based on phonological processes and constraints. In the absence of evidence from phonological processes, conclusions about featural representation are almost entirely speculative. There is, however, good phonological evidence concerning the uvulars and pharyngeals in some of the languages of the Pacific Northwest. Nevertheless, to keep the survey to manageable proportions, I have deliberately confined my attention to the Semitic languages with occasional excursions into broader Afro-asiatic. ${ }^{2}$

\section{X.2 Gutturals within Distinctive Feature Theory}

X.2.1 The Articulatory and Acoustic Properties of Gutturals

To provide a secure basis for the subsequent discussion, I will begin by reviewing the abundant phonetic evidence for the properties of gutturals in Arabic, a language with the full suite of six. This review takes each of the three types of gutturals (laryngeal, pharyngeal, and uvular) in turn, first examining their articulatory and then their acoustic properties. This section concludes with a summary of the characteristics of gutturals, taking special note of the properties common to all of them.

There is no body of articulatory data that specifically deals with the production of the laryngeals $\underline{?}$ and $\underline{h}$ in Arabic (though see section X.5) Al-Ani (1970) reports that he made cineradiograms of the Arabic laryngeals but was unable to interpret them usefully. Acoustically, the laryngeals are characterized by a complete lack of formant transitions or other effects on adjacent vowels (Klatt and Stevens 1969; also see Younes 1982 on the "neutral environment"), as is typical of laryngeals in other languages (Stevens and House 1963:116). During the production of $\underline{h}$, the resonances of the vocalic context are weakly excited by fricative-like 
noise (voiced intervocalically) (Al-Ani 1970, Klatt and Stevens 1969). The $\underline{?}$ is realized sometimes by an obvious stop, sometimes only by creaky voice quality.

Interpreting the acoustic evidence in articulatory terms, we would have to say that $\underline{?}$ and $\underline{h}$, although they involve an obvious laryngeal gesture, do not have any constriction higher in the vocal tract (discounting coarticulatory effects from surrounding vowels). In particular, there is no evidence for a pharyngeal or uvular constriction accompanying the glottal gesture. Even raising of the larynx during production of the consonant (a conspicuous property of the pharyngeals) should produce a falling transition of the second formant in a following vowel as the larynx returns to its normal position. Therefore the entire burden of producing the laryngeal consonants falls on the larynx.

Ghazeli (1977) describes in some detail the results of a cineradiographic investigation of the pharyngeals $\underline{I}$ and $\underline{\hbar}$. (There are similar studies by Delattre (1971) on Lebanese and Bukshaisha (1985) on Qatari; their results do not appear to differ significantly from Ghazeli's.) The main gesture in the production of the pharyngeals is an approximation of the posterior wall of the laryngopharynx and the tongue root from the epiglottis down to the larynx. Both the posterior pharyngeal wall and the tongue root are moved inward from their rest positions. Concomitantly, the larynx itself and adjoining structures are raised considerably. The constriction is significantly narrower for $\underline{\hbar}$ than for $\underline{I}$. (Delattre points to a perceptual basis for this; the increased friction in the voiceless approximant compensates for its otherwise lower amplitude.) Apparently for mechanical reasons, the tongue dorsum is concave during the production of $\underline{\hbar}$.

The place of articulation of $\underline{\underline{S}}$ and $\underline{\hbar}$, then, is the lower pharynx. The active articulator is some combination of the tongue root and the epiglottis. Laufer and Condax (1979) observed the epiglottis with a fiberscope during the production of pharyngeals by Sephardic Hebrew 
speakers and concluded that the epiglottis was retracting independently of the tongue root. Against this, Boff Dkhissi (1983, cited by Butcher and Ahmad (1987)) concluded on the basis of a cinefluorographic investigation of Moroccan Arabic that both tongue root and epiglottis were involved. ElHalees (1985) has published a xeroradiogram of an Iraqi Arabic speaker producing $\{$ as an epiglottal stop made with considerable retraction of the tongue root. Thus, it seems likely that both the tongue root and the epiglottis are being actively recruited to make the pharyngeal constriction.

Neither Delattre nor Ghazeli made films of pharyngeals in different vocalic contexts. Thus, although we see some raising of the anterior portion of the tongue body during the pharyngeals, we cannot know whether this is the influence of the vowel or an additional requirement of the pharyngeal consonants. In the actual tokens that Ghazeli examined, the

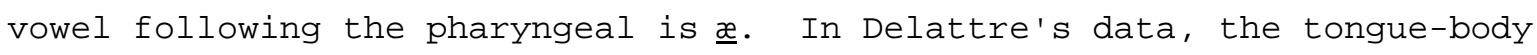
position also looks fairly $\underline{-l i k e . ~}$

Acoustically, we expect to find a high F1 in pharyngeals, and that is what the literature shows (Al-Ani (1970, 1978), Ghazeli (1977), Klatt and Stevens (1969), Alwan (1986), Butcher and Ahmad (1987)). Butcher and Ahmad

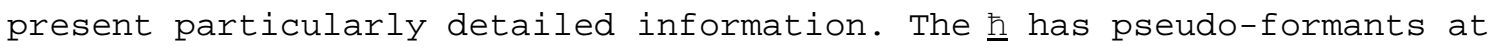
around $700-900 \mathrm{~Hz}, 1600-2200 \mathrm{~Hz}$, and $2200-3000 \mathrm{~Hz}$. At the consonant/vowel boundary of $\underline{S}$, F2 is relatively low, in the $1200-1400 \mathrm{~Hz}$ range. F1 is high -- 900-1000Hz -- although it is somewhat lower before the round vowels u: and $\underline{0}$ : The spectrum of $\underline{\hbar}$ is roughly the same, although $F 1$ is not quite as high. The major effect of the pharyngeals on the steady-state portions of the adjoining vowels is significant raising of $\mathrm{F} 1$, by about $100 \mathrm{~Hz}$ relative to a neutral (glottal) environment.

The voiceless pharyngeal $\underline{\hbar}$ is some kind of fricative or approximant (or perhaps even a glide). The realizations of $\underline{\mathfrak{S}}$ vary dialectally or even individually between a stop (presumably epiglottal) and an approximant or fricative. Al-Ani (1970) found that he and three Iraqi informants produced 
I as a stop (cf. El-Halees 1985). In contrast, Ghazeli (1977) did not find stopped $\{$ with any of his informants, including one Iraqi. In Ghazeli's spectrograms the $\{$ looks very much like a glide in intervocalic position. Butcher and Ahmad (1987) had three Iraqi informants, and found stop bursts at the release of $\underline{I}$ about $60 \%$ of the time. (These were initial and final; they did not look at medial pharyngeals.) There are no phonological consequences of the superficial dialectal distinction between stop and continuant $\{$ s in Arabic. But, according to Catford (1983: 347), there is a Caucasian language ("the Burkikhan dialect of the Dagestanian language Agul") which does have distinct stop and continuant $\{$ phonemes. Another possibility of phonemic contrast is that between plain and glottalized $\underline{\text {, }}$ found in Columbian Salish (Kinkade 1967).

Further properties of $\underline{\underline{S}}$ and $\underline{\hbar}$ involve the larynx. I have already noted that the larynx is considerably raised during the production of the pharyngeals (Ghazeli 1977), and $\underline{I}$ is often accompanied by creaky voice. This phenomenon is probably not unique to Arabic; Hayward and Hayward (1989), citing Sasse (1979) and Hayward (1989), note that $\underline{I}$ is frequently "glottalized" in Ethiopian (Semitic and Cushitic) languages.

Could laryngeal involvement in the production of pharyngeals explain the class of gutturals? Both types of laryngeal effects in pharyngeals, larynx raising and creaky voice, have plausible mechanical explanations. The raising of the larynx in pharyngeals is probably a side-effect of the gestures involved in narrowing the pharynx. Ladefoged $(1975,143)$ has speculated that the creakiness of $\{$ comes about "because the necessary constriction in the pharynx also causes a constriction in the larynx". Furthermore, Laufer and Condax $(1979,52)$ point out that the creakiness is consistent with compression of the top of the arytenoids by the retracted epiglottis (as in swallowing). If laryngeal involvement in pharyngeals is superficial mechanical effect, than it is unsuitable as an explanation for a truly phonological property like the guttural class, with effects throughout the phonology. ${ }^{3}$ 
Finally, we turn to the uvular gutturals $\underline{b}$ and $X$. Again, Ghazeli (1977) presents x-ray data that differs only slightly from the data in Delattre (1971). The uvulars are produced with a much higher and slightly narrower constriction than the pharyngeals. This constriction is obtained by raising and retracting the dorsum of the tongue toward the posterior wall of the oropharynx. In $\underline{\underline{b}}$, the uvula is curved downward and anteriorly to produce a trill. The constriction in $\boldsymbol{X}$ is narrower than that in $\underline{\underline{b}}$, and this is associated with a slight raising of the larynx (supporting the earlier claim that larynx raising in pharyngeals is purely a mechanical effect).

Acoustically, $\mathbf{X}$ is characterized by very low frequency noise, below $1200 \mathrm{~Hz}$. The consonant $\underline{\mathrm{k}}$ has formants at $500-600 \mathrm{~Hz}$ and $1200-1300 \mathrm{~Hz}--$ in other words, F1 is high, but not as high as in the pharyngeals. F2 is as low as in the pharyngeals. The lower F1 of the uvulars compared to the pharyngeals is consistent with the fact that they are produced quite close to the midpoint of the vocal tract. The $x$ is a voiceless fricative or approximant; the usual realization of $\underline{\underline{k}}$ is a voiced trill.

This completes the review, and we can now sum up the observations about the phonetic properties of gutturals:

(i) Active articulator. The gutturals are produced by three distinct gestures: a purely glottal one in the laryngeals, retraction of the tongue root and epiglottis and advancement of the posterior wall of the laryngopharynx in the pharyngeals; and a superior-posterior movement of the tongue dorsum in the uvulars. (ii) Place of articulation. The gutturals are all produced in the posterior region of the vocal tract.

(iii) Spectrum. The gutturals all have relatively high F1. F1 is at the theoretical maximum in the case of laryngeals, close to the maximum for the pharyngeals, and higher than any orally articulated consonants in the case of uvulars. 
(iv) Stricture. All gutturals except $\underline{?}$ meet Catford's (1977: 122) definition of approximant: "non-turbulent flow when voiced; but the flow becomes turbulent when they are made voiceless". Clements (1990) modifies this definition to require oral stricture in nonapproximants. With this modification, even $\underline{?}$ is included in the class of approximants. ${ }^{4}$

Crucially, the gutturals share posterior place of articulation, high F1, and stricture (see section X.4); the gutturals do not share active articulator.

\section{X.2.2 Previous Featural Treatments of Gutturals}

There are many ways to organize a system of distinctive features. The

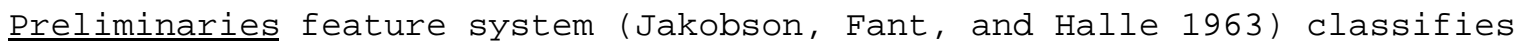
sounds in acoustic terms, even if they are articulatorily quite dissimilar (like [+grave] $\underline{\mathrm{k}}$ and $\underline{\mathrm{p}}$ ). The $\underline{\mathrm{SPE}}$ feature system (Chomsky and Halle 1968) is primarily oriented toward the active articulator, effecting a major four-way classification of consonants by the features [coronal] and [anterior], with finer distinctions supplied by features like [distributed], [high], [low], and [back]. Ladefoged (1975) and Williamson (1977) propose a many-valued place feature that essentially measures distance from the glottis, taking values like [[pharyngeal]place] or [1Place].

The acoustically-based Preliminaries system, applied to Arabic by Jakobson (1957), maps low F2 onto the single feature [flat]. The [+flat] consonants of Arabic are the uvulars and the emphatics (see section X.4). Stretching the point a bit, Jakobson classifies the pharyngeals as [+flat] as well. Since $\mathrm{F} 2$ is not low in the laryngeals, though, there can be no natural class of the gutturals defined by the feature [flat]. Additional problems arise from the identification of [flat] with rounding, which is indepedent of uvular or pharyngeal place of articulation. 
Problems with the SPE treatment of gutturals have been previously noted by Kenstowicz and Kisseberth (1979: 250) and Keating (1988: 7-8). The following chart gives the values of the relevant features for the gutturals and for other places of articulation found in Semitic, according to Chomsky and Halle $(1968,307)$ :

(1)

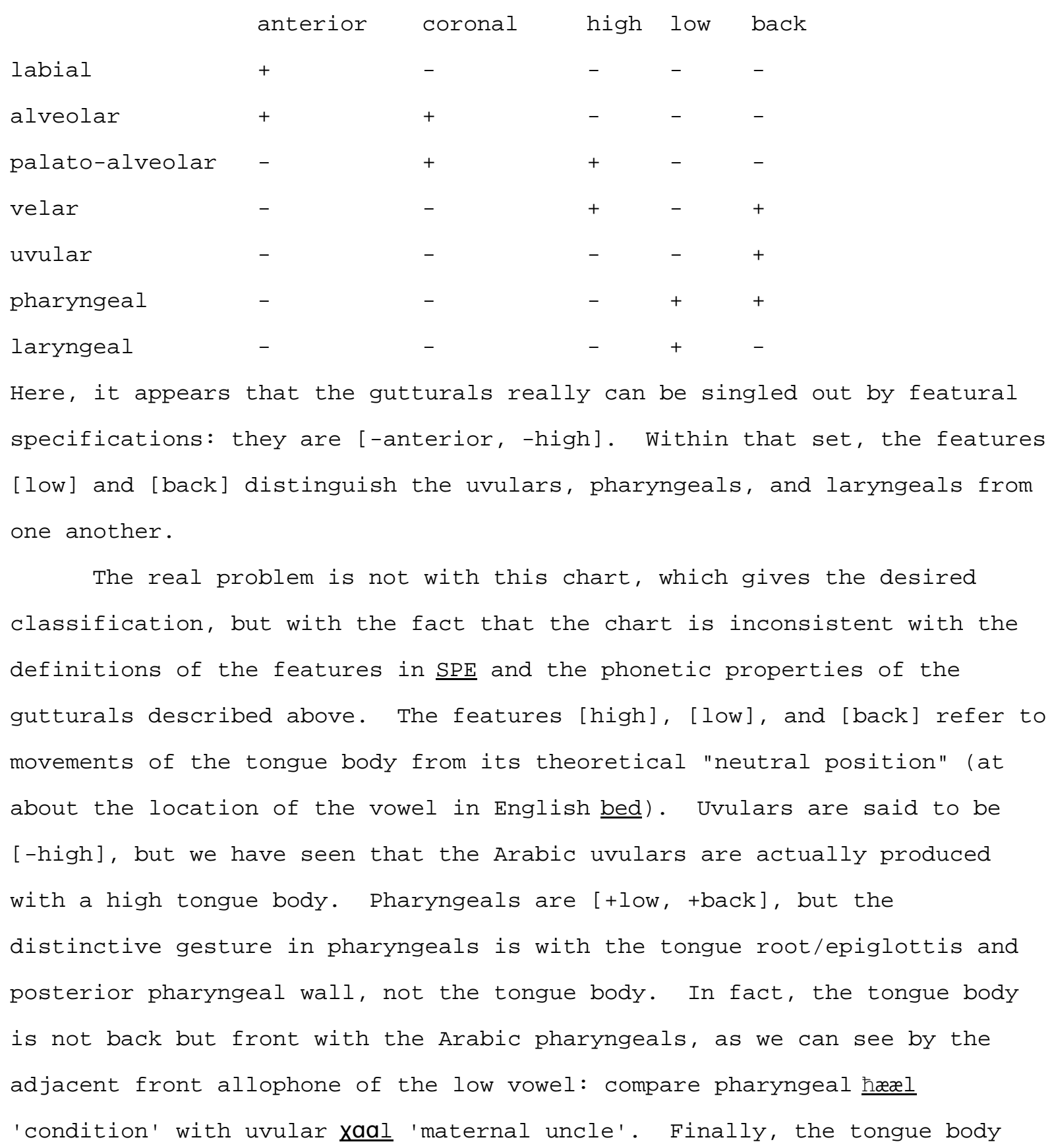


cannot be implicated in the production of the laryngeals at all; thus, the assignment of [+low] to laryngeals is simply inconsistent with the definition of [low] as a feature referring to tongue height.

Even if these problems with the SPE system could be set aside, there would be good reason to reject the [-anterior, -high] characterization of the gutturals. As Sagey (1986) and McCarthy (1988) show, this sort of cross-classificatory use of [anterior] presents major difficulties in the context of feature theory as a whole.

The multi-valued [place] feature of Ladefoged (1975) and Williamson (1977) does provide a natural classification of the gutturals: they are the three places of articulation closest to the glottis. Formally, in a theory with numerical feature coefficients, the gutturals are the class [0C2place]. The problem is that, as a theory of consonantal place classifications, this is far too weak. Although the gutturals are clearly a natural class in Semitic, this theory permits classifications of contiguous places that are rare or nonexistent: labial, labiodental, and dental; labiodental, dental, and alveolar; velar, uvular, and pharyngeal; and so on. Although certain sets of contiguous places of articulation do indeed constitute natural classes, contiguity alone is not enough to make a class natural.

Recent phonological research on distinctive features (beginning with Anderson 1971 and taken up by Halle 1983, Sagey 1986, Halle 1988, McCarthy 1988, Maddieson and Ladefoged 1988, and others) has developed a model that places very rigid restrictions on reference to "place of articulation" in consonant systems. In this theory, speech sounds are principally classified by active articulator. The fruit of this work is a set of three features that refer to the active articulator. The [labial] sounds are produced by raising or protruding the lower lip (and possibly the upper one as well). Thus, they include true labials, labiodentals, and, as a secondary articulation, lip-rounding. The [coronal] sounds are produced by raising the tongue tip or blade. They include the dentals, alveolars, 
palato-alveolars, retroflexes, and, as a secondary articulation, apicalization. Finally, the [dorsal] sounds, made by moving the tongue body from its neutral position, include the vowels, the palatals, velars, and uvulars, and, as a secondary articulation, velarization and perhaps palatalization. The obvious extension of this approach to pharyngeals posits a fourth active articulator, [tongue root] or [radical] (McCarthy (1985), Cole (1987), Maddieson and Ladefoged (1988)).

But even if we add [radical] to the set of articulator features, the model fails to account for the fact that gutturals are a natural class. Gutturals are produced by three distinct active articulators, the larynx, the tongue root and epiglottis (that is, [radical]), and the tongue body (that is, [dorsal]). Thus, a natural class of gutturals is incompatible with the fundamental assumption of articulator-based feature theory.

\section{X.2.3 [pharyngeal] Place}

Since the gutturals do not share a single major articulator, we should instead ask what they do have in common. All gutturals are produced by a constriction in the same region of the vocal tract. "Region" here must be broadly defined, to encompass the area from the larynx inclusively to the oropharynx. Three different articulators have access to that region -- the larynx, the tongue root, and the tongue body. The defining characteristic of the gutturals is not the major articulator, but the place of articulation, characterized by the feature [pharyngeal].

This account, though, leads to a major asymmetry. The anterior part of the vocal tract is organized in terms of active articulator, but the posterior part is organized in terms of place of articulation. More strikingly, the three active articulator features [labial], [coronal], and [dorsal] divide up a region of the vocal tract approximately equal in length to the region subtended by the single feature [pharyngeal]. In other words, the asymmetry is that finer distinctions of place are made in the front of the vocal tract than in the back. 
An explanation for this asymmetry comes from examining the relation between phonological features and speech production. In the articulatorbased theory, each of the features [labial], [coronal], and [dorsal] can be thought of as "driving" the corresponding active articulator (Halle 1983). In contrast, Perkell (1980) has proposed that distinctive features are: orosensory patterns corresponding to distinctive sound producing states. These 'orosensory' patterns consist of proprioceptive, tactile and more complicated air-pressure and airflow information from the entire vocal tract. ... As examples, the orosensory goals for the features 'high' and 'back' might consist of specific patterns of contact of the sides of the tongue body with the teeth and the pharyngeal wall. The orosensory goal for the feature 'coronal' might be contact of the sides of the tongue blade with the teeth or alveolar ridge... (Perkell 1980, 338)

The vocal tract can report its state through feedback mechanisms like touch or proprioception. Distinctive features are defined as particular patterns of feedback from the vocal tract (which have consistent acoustic consequences) .

The proposed feature [pharyngeal], then, would be defined as the orosensory pattern of constriction anywhere in the broad region of the pharynx. The corresponding "distinctive sound producing state" of [pharyngeal] is high F1, a property that the gutturals share. ${ }^{5}$

If features are defined as orosensory goals rather than articulatory instructions, we expect that differences in the acuity of orosensation at different points in the vocal tract will be reflected in the phonological organization imposed on those regions. In particular, the large [pharyngeal] region should be rather poorly differentiated compared to the smaller [labial], [coronal], and [dorsal] regions.

There are three sources of evidence for differences in sensory acuity in the vocal tract. All of these do indeed support the model proposed here, where the wide [pharyngeal] region is treated as equivalent to the 
narrower [labial], [coronal], and [dorsal] regions. None of the evidence is perfect, though, so the argument at this point becomes somewhat speculative.

First, the actual distribution of sensory neurons in the vocal tract corresponds quite well to our expectations. In a comprehensive survey of the histological literature, Grossman (1964) concludes:

This review of the reported oral sensory nerve elements reveals a progressive decrease in the frequency of sensory endings from the front to the rear of the mouth in humans... These findings are compatible with the author's initial experimental evidence which indicates that tactile discriminations are most acute in the anterior mucosal surfaces of the mouth. It is probably not coincidental that many important speech articulatory phenomena occur in the same oral region. (Grossman 1964: 132)

Second, direct measurements of sensory acuity can be obtained from experiments determining the minimal distance for two-point discrimination, in which subjects are asked to report whether they feel two points rather than one from a caliper-like device. Ringel (1970) performed such an experiment on four regions of the vocal tract at the midline and right and left sides. The results (means of 25 subjects, in millimeters, followed by standard deviations) are as follows:

$\begin{array}{llll} & \text { Left } & \text { Middle } & \text { Right } \\ \text { Upper Lip } & 2.47(.84) & 2.31(.72) & 2.49(.69) \\ \text { Tongue Tip } & 1.82(.41) & 1.70(.46) & 1.72(.47) \\ \text { Alveolar Ridge } & 3.21(1.39) & 2.66(1.09) & 3.20(1.29) \\ \text { Soft Palate } & 2.95(1.17) & 2.64(1.10) & 3.06(1.26)\end{array}$

Unfortunately, there are no measurements of two-point discrimination for the tongue-body or the pharynx. (The apparatus is rather large and would probably excite the faucal gagging reflex.) Certainly, what we do see are differences in sensory acuity among different regions of the vocal tract. 
Furthermore, the tongue tip, an articulator that is associated with several phonological features ([coronal], [distributed], and [anterior]) is unusually sensitive.

Third, another kind of evidence for the relative lack of pharyngeal sensory differentiation comes from the observation that the size of the cortical projection of a body part corresponds to its sensory acuity. Penfield and Rasmussen's (1950) sensory homunculus, deduced from experiments involving low-voltage stimulation of the cortex in conscious patients undergoing brain surgery, shows that the whole pharynx is about half the size, sensorily speaking, of the tongue, which includes two articulators. There may also be a similar equivalence for the lips. 6

The available evidence on differential sensitivity within the oral vocal tract is not wonderfully detailed, but it is sufficient to provide at least some support for the following speculation. With respect to orosensation, the regions of the vocal tract covered by each of the features [labial], [coronal], [dorsal], and [pharyngeal] may be equal in subjective size. To be more precise, imagine determining a subjective unit of measurement for each region of the vocal tract based on the minimum distance of two-point discrimination in that region. The objective size of this subjective unit will vary at different points in the vocal tract, being much greater in the more poorly innervated posterior regions. Measured in these "cognitive units", the different regions of the vocal tract might be of approximately equal size. Morever, the regions themselves can be defined as areas where the objective size of the cognitive unit of measure is roughly constant. In this way, orosensation provides a kind of quantization of the vocal tract into featural regions, as Perkell (1980) suggests. Since the anterior active articulators contribute significantly to orosensation (the lower lip and the tongue tip being particularly sensitive), the correspondence between active articulators and the place features [labial], [coronal], and [dorsal] is not so unexpected. 
The orosensory target model is not the only possible approach to the problem posed by the feature [pharyngeal]. One obvious alternative is that the pharynx has a uniform characterization in motoric terms. Clearly this is not true at the lowest level: the uvular constriction is presumably made primarily by a gesture of the styloglossus, while the true pharyngeals $\underline{I}$ and $\underline{\hbar}$ are formed by the pharyngeal constrictors and the glottals are made by the intrinsic muscles of the larynx. But it is certainly possible that these consonants form a motoric unity at some much higher level.'

Another approach to [pharyngeal] place is suggested by Hess's (1990)

work. Hess presents a factor analysis (see Jackson 1988) based on $x$-ray tracings from two speakers of Damascene Arabic and one speaker of Tunisian. The segments with pharyngeal articulation include the pharyngeal consonants $\underline{I}$ and $\underline{\hbar}$, the emphatics $\underline{S}$ and $\underline{T}$, the vocalic near-phonemes $\underline{\mathbf{a}}$ and $\underline{æ}$, and the vocalic allophones $\underline{I}$ and $\underline{\mathrm{U}}$. Non-pharyngeals in the data set are $\underline{\mathrm{k}}, \underline{\mathrm{t}}, \underline{\mathrm{s}}$, $\underline{i}$, and $\underline{u}$.

One factor that she obtains corresponds to retraction of the tongue root along a horizontal axis through the epiglottis, accompanied by raising of the larynx and posterior movement of the upper pharyngeal wall. This factor basically distinguishes pharyngeal articulation from non-pharyngeal, and Hess characterizes it by the feature [radical]. The other factor involves lowering the tongue dorsum, retracting the tongue root, and raising the larynx. This factor distinguishes the low pharyngeals $\underline{\hbar}, \underline{\mathbf{S}}, \underline{\mathbf{a}}$, and $æ$ from the others, and Hess characterizes this factor as [low].$^{8}$

The most relevant aspect of Hess's study is the conclusion that the same factor is responsible for the pharyngeal constriction in both pharyngealized coronals like $\underline{S}$ and $\underline{T}$ and primary pharyngeals like $\underline{S}$ and $\underline{\hbar}$, despite the fact that these pharyngeal constrictions are widely separated from one another. As Hess (1990: 13) observes, "Factor analysis has ascribed the difference to the influence of the tongue blade in the pharyngealized segments and given us one factor for retraction." The uvulars $\underline{\mathbf{b}}, \mathbf{X}$, and $\underline{\mathbf{q}}$ have a constriction in the upper pharynx very similar 
to that of $\underline{S}$ or $\underline{T}$, so it is important to know whether the same factor could produce upper pharyngeal retraction for them. Unfortunately, Hess did not include the uvulars in her study, so this approach must remain speculative for now.

To sum up, the guttural class is defined by the place of articulation feature [pharyngeal]. I have suggested that the basis for such a broad class, encompassing about half the length of the vocal tract, can be found in Perkell's (1980) notion of distinctive features as correlations of distinctive acoustic events and orosensory targets. Differences between [pharyngeal] and other place or articulator features plausibly follow from the large differences between the pharynx and the oral vocal tract in sensory innervation.

\section{X.3 Evidence for the Natural Class of Gutturals}

We now turn to the phonology, considering a number of arguments for the gutturals as a natural class. Evidence comes primarily from the synchronic phonology of semitic languages, with occasional forays into the Cushitic material adduced by Hayward and Hayward (1989). The material is classified according to the phonological role of the guttural class: cooccurrence restrictions, vowel lowering, avoidance of syllable-final position, and degemination. We shall also look at some historical changes affecting gutturals in semitic.

The following chart gives the consonant system of Standard Arabic; all of the consonants in the columns labeled Emphatic, Uvular, Pharyngeal, and Laryngeal have [pharyngeal] components in their articulation: 
(3)

\begin{tabular}{|c|c|c|c|c|c|c|}
\hline Labial & Coronal & Emphatic & Velar & Uvular & Pharyngeal & Laryngeal \\
\hline & t & $\mathrm{T}$ & k & q & & $?$ \\
\hline $\mathrm{b}$ & $\mathrm{d}$ & $\mathrm{D}$ & $g$ & & & \\
\hline$f$ & $\theta, \mathrm{s}$ & S & & $x$ & $\hbar$ & $\mathrm{h}$ \\
\hline & ð, z & Z & & в & $\uparrow$ & \\
\hline
\end{tabular}

m

$\mathrm{n}$

$$
\mathrm{w}, \mathrm{Y}
$$

Original $\underline{q}$ is realized by many speakers as the palatoalveolar affricate $\mathbf{d}_{3}$; nevertheless, it patterns as a velar with respect to the root cooccurrence restrictions (section X.3.1) and assimilation of the definite article in Standard Arabic. The consonants with a [pharyngeal] constriction include the gutturals $\mathbf{X}, \underline{\underline{b}}, \underline{\hbar}, \underline{\underline{l}}, \underline{?}$, and $\underline{h}$, the uvular stop $\underline{q}$, and the pharyngealized coronals or "emphatics" $\underline{T}, \underline{D}, \underline{S}$, and $\underline{Z}$. The phenomena I will be analyzing throughout this section affect only the gutturals proper,

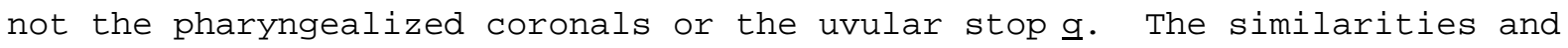
differences between gutturals and other consonants with [pharyngeal] constriction are discussed in section $\mathrm{X} .4$. Since the evidence comes mostly from a single language family, Semitic, an objection naturally comes to mind. Could the natural class of gutturals be an idiosyncratic property of this language family, with no bearing on a universal feature theory? The notion "idiosyncratic property of a language family" makes sense only as a claim about language history. But a phonological rule referring to gutturals that is an innovation in a particular semitic language cannot be inherited from the proto-language; in this case, appeal to a semitic idiosyncrasy is purely mystical, since there is no mechanism by which language learners might discover this idiosyncrasy and apply it in a novel rule. The only sensible account is that the 
natural class of gutturals is already available to language learners from linguistic theory; they could not discover it from their semitic heritage.

\section{X.3.1 Root Consonant Cooccurrence Restrictions on Gutturals}

The lexicon of the Semitic languages is organized around a sequence of two, three, or four consonants called the root. It has long been known that certain combinations of consonants in the same root are avoided, although this matter was not investigated systematically until Greenberg (1950). Since then, other studies (McCarthy 1985, Mrayati 1987) have looked at the evidence with different lexical material and different statistical methods and have extended the results to other languages (Amharic (Bender and Fulass 1978), Hebrew (Koskinen 1964), Qafar (Hayward and Hayward 1989)) .

The basic observation is that consonants within the same root cannot be homorganic (with certain qualifications). In Arabic, roots rarely or never contain adjacent consonants from any of the following sets:

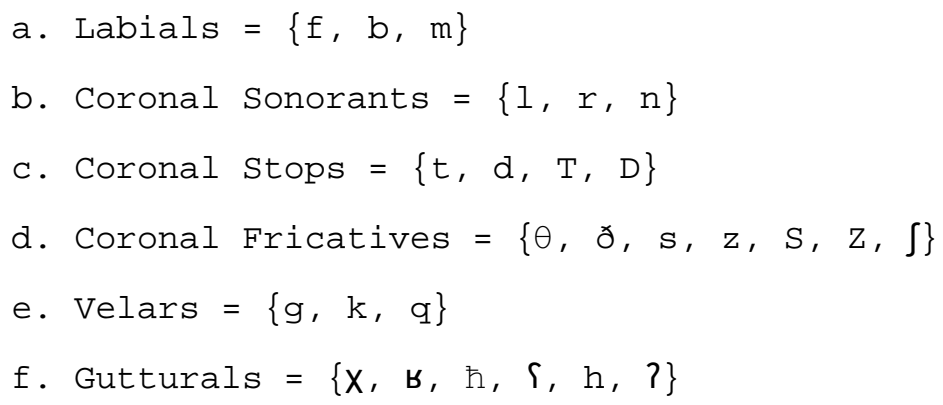


the order row-column. For example, the root ktb is counted twice, in row $\underline{g k}$, column $\underline{t d}$, and in row $\underline{t d}$, column $\underline{b f m}$. Outlining and shading highlight cells with frequencies significantly lower than expected (shaded: p < .05; outlined: $\mathrm{p}<.005 ; \mathrm{X}^{2}$ on 1 degree of freedom). Since Arabic independently disallows adjacent identical root consonants (McCarthy 1981, 1986), these combinations were not included in the computation of expected frequencies. Cells containing $X$ have 0 frequency because of this prohibition on adjacent identical consonants.

(5)

\begin{tabular}{|c|c|c|c|c|c|c|c|c|c|c|c|c|c|c|c|}
\hline & $\mathrm{bfm}$ & $\mathrm{td}$ & TD & • ठ & $\mathrm{sz}$ & $\mathrm{SZ}$ & $\int$ & gk & $q$ & $\mathrm{XB}$ & $\int \hbar$ & $? \mathrm{~h}$ & $\operatorname{lr}$ & $\mathrm{n}$ & wy \\
\hline $\mathrm{bfm}$ & 0 & 76 & 57 & 24 & 68 & 28 & 32 & 43 & 43 & 31 & 79 & 44 & 180 & 40 & 91 \\
\hline td & 68 & 4 & 0 & 2 & 9 & 0 & 6 & 17 & 11 & 10 & 32 & 21 & 69 & 20 & 51 \\
\hline TD & 61 & 4 & 0 & 0 & 5 & 0 & 5 & 4 & 5 & 9 & 25 & 11 & 59 & 14 & 38 \\
\hline • ठ & 29 & 0 & 0 & 0 & 0 & 0 & 0 & 6 & 7 & 4 & 5 & 9 & 44 & 3 & 24 \\
\hline sz & 87 & 17 & 7 & 0 & 0 & 0 & 0 & 31 & 20 & 19 & 40 & 24 & 75 & 21 & 65 \\
\hline SZ & 52 & 15 & 0 & 0 & 0 & 0 & 0 & 1 & 5 & 4 & 16 & 7 & 38 & 5 & 24 \\
\hline $\int$ & 41 & 14 & 10 & 3 & 1 & 2 & $x$ & 19 & 9 & 11 & 24 & 10 & 33 & 8 & 37 \\
\hline gk & 75 & 33 & 2 & 16 & 46 & 4 & 11 & 1 & 0 & 1 & 29 & 24 & 90 & 29 & 47 \\
\hline q & 51 & 19 & 19 & 7 & 11 & 15 & 10 & 0 & $x$ & 0 & 22 & 6 & 45 & 12 & 31 \\
\hline XB & 70 & 18 & 31 & 13 & 23 & 13 & 11 & 2 & 1 & 0 & 2 & 0 & 63 & 13 & 42 \\
\hline $\int \hbar$ & 91 & 42 & 29 & 17 & 35 & 27 & 18 & 34 & 22 & 0 & 0 & 2 & 83 & 28 & 60 \\
\hline ?h & 67 & 32 & 10 & 10 & 29 & 4 & 8 & 25 & 6 & 3 & 2 & 2 & 65 & 16 & 54 \\
\hline lr & 149 & 51 & 36 & 15 & 58 & 20 & 20 & 66 & 48 & 29 & 74 & 42 & 0 & 14 & 91 \\
\hline $\mathrm{n}$ & 55 & 23 & 19 & 7 & 26 & 12 & 14 & 31 & 26 & 16 & 28 & 21 & 2 & $\mathrm{X}$ & 51 \\
\hline wy & 83 & 44 & 31 & 14 & 44 & 14 & 18 & 34 & 33 & 20 & 49 & 29 & 89 & 26 & 21 \\
\hline
\end{tabular}

Similar observations can be made about non-adjacent root consonants $\underline{k}$ and $\underline{b}$ in the root $(\underline{\mathrm{kt}})$, but the effects are not as robust.

Our particular concern, of course, is with the gutturals. Roots combining two gutturals are significantly infrequent. If gutturals freely 
combined in roots, we would expect to have 114 roots containing adjacent non-identical gutturals, but in fact there are just 11. (For non-adjacent gutturals, the expected frequency is 79 and the observed frequency is 36. ) Inspection of (5) shows that the whole guttural class defines a block of cells with 0 frequency, significantly low frequency, or both. Thus, this phenomenon requires reference to the gutturals as a natural class.

Formal accounts of the Semitic root cooccurrence restrictions and similar dissimilatory constraints begin with McCarthy (1985) and continue with Mester (1986), Yip (1989), Selkirk (1988), Dresher (1989), and Padgett (1991). The last three studies have most strongly influenced the refinements I offer here.

In the simplest case, that of the prohibition against a root containing two labials, we need to rule out hypothetical representations of a non-occurring root like *fbt:

a.

b.

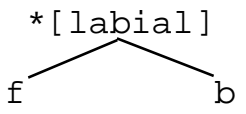<smiles>C[10BH][101In]</smiles>

f

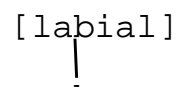

b [coronal]

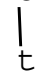

[corponal]

It is reasonable to suggest that the branching configuration in (6a) is ruled out universally from underlying representations; it can arise only in derived representations, through the application of Place Assimilation. This principle can be formulated as follows:

(7) No-Branching Condition

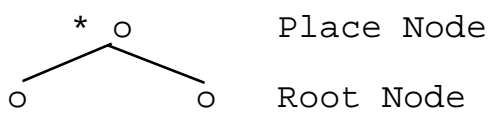

The No-Branching Condition prohibits representations that contain a single Place node branching to two Root nodes. This constraint holds of underlying representation but is explicitly overridden by rules of Place Assimilation in Arabic and elsewhere. ${ }^{9}$ 
The other way to represent a prohibited root like flbt is (6b), with two instances of the feature [labial]. The impossibility of (6b) is determined by the Obligatory Contour Principle (Leben 1973, Goldsmith 1976, McCarthy 1981, 1986), formulated most generally as in (8):

(8) Obligatory Contour Principle (OCP)

Adjacent identical elements are prohibited.

The OCP functions categorically in Arabic phonology to exclude adjacent identical consonants within a root -- thus, applied to entire segments, it absolutely prohibits roots like CIS or $\underline{\text { SC }}$ (MCCarthy 1981, 1986).

Dresher (1989), Selkirk (1991), and Padgett (1991) have suggested that the scope or domain of the OCP can be limited by statements restricting its applicability to a particular feature in a particular context. Specifically, in the phonology of Arabic, the features [continuant] and [sonorant] define separate domains of cooccurrence for [coronal]:

(9) Domain of OCP

$$
\begin{aligned}
& \text { a. [coronal] / } \\
& \text { [ } \alpha \text { cont ] } \\
& \text { b. [coronal] / }
\end{aligned}
$$

The first restriction on the scope of the OCP is not absolute, since there is a weaker prohibition on roots containing two coronals that differ in [continuant]. ${ }^{10}$

Subject to these qualifications, the system described will mark as ill-formed any root containing two homorganic consonants. The system, via the OCP and (7), refers to [pharyngeal] as well as the familiar Place features [labial], [coronal], and [dorsal]. In this respect, the feature defining the guttural class functions like all other features characterizing a place of articulation or active articulator. 
X.3.2 Vowel Lowering in Guttural Context

In the basic derivational class of the Arabic verb, perfect and imperfect verbs alternate in the quality of the thematic vowel, the last vowel of the stem: katab 'wrote', yaktub 'writes'. Roots are assigned to one of five Ablaut classes according to which thematic vowels they have in the perfect and imperfect. The following chart gives the frequency of the five types, based on all relevant verbs (including doublets) occurring in Wehr (1971):

Ablaut Class

$\mathrm{a} / \mathrm{u}$

$a / i$

i / a

a / a

$\mathrm{u} / \mathrm{u}$
Example

katab/yaktub

Darab/yaDrib

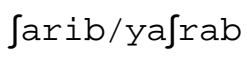

faSal / yafSal

balud/yablud 'write'

'beat'

'drink'

'do'

'be stupid'
Frequency

1029

842

518

436

191

Membership in the $\underline{u} / \mathrm{u}$ class is semantically determined; all $\underline{u} / \mathrm{u}$ verbs are statives. The $i / a$ class is often intransitive or stative, but not invariably so. Membership in classes a/u or a/i is entirely unpredictable -- that is, it must be specified for each lexical item. ${ }^{11}$

Membership in the a/a Ablaut class, though, is phonologically conditioned. Of the 436 a/a verbs, 411 contain a guttural consonant adjacent to the imperfect thematic vowel a. Examples include verbs like faSal/yaflal 'do' with the guttural preceding the ablauting vowel and verbs like radal/yardal 'prevent' with the guttural following the ablauting vowel. The thematic vowel a replaces $\underline{u}$ or $\underline{i}$, which are not usually found in the imperfect of guttural roots.

The lowering of the thematic vowel under adjacency to a guttural is paralleled by raising triggered by a high glide $\underline{w}$ or $\underline{y}$. An examination of roots containing both a guttural and a high glide shows that the high glide 
prevails in case of conflict. There is, then, a rule raising vowels near

high glides that undoes the effect of lowering next to a guttural.

Besides this pattern, there is a significant residue of 118 guttural

verbs that do not evidence lowering, although about half (55) have lowering as a variant pronunciation. Curiously, the uvular gutturals are represented disproportionately among these exceptions:

$\begin{array}{llll}\text { Guttural } & \text { Frequency in } & \text { Number of } & \text { Ratio } \\ & \text { Root II/II } & \text { Exceptions } & .05 \\ \text { h } & 114 & 6 & .15 \\ \text { S } & 138 & 21 & .13 \\ \hbar & 234 & 30 & .16 \\ \text { B } & 183 & 30 & .30 \\ \text { X } & 66 & 20 & .36\end{array}$

That is, there are about twice as many exceptions to Guttural Lowering among the uvulars as there are among the pharyngeals, though the laryngeals and pharyngeals clearly pattern alike. This is perhaps related to the fact that the uvular gutturals have some of the characteristics of complex segments, with simultaneous [pharyngeal] and [dorsal] specifications (see section X.4).

We have now extablished an accurate descriptive generalization and so we can consider how to formulate the rule. The central question is why gutturals have a lowering effect on vowels. There is abundant phonetic evidence that low vowels involve some pharyngeal constriction (Delattre 1971, Perkell 1971, Wood 1979), with concomitant acoustic similarities between $\underline{a}$ and the gutturals (high F1). Clearly, this requires that [pharyngeal] be assigned to low vowels as well as guttural consonants. This is close to the position in SPE, where low vowels, pharyngeals, and laryngeals are all [+low]. It is also the view taken by Perkell (1971), based on Halle and Stevens (1969), where low vowels and pharyngeal 
consonants are marked [Constricted Pharynx] (cf. Kiparsky (1974)) . Recent work by van der Hulst (1988), Hayward and Hayward (1989), Gorecka (1989), Lowenstamm and Prunet (1989), Prunet (1990), Herzallah (1990), and Selkirk (1991) further pursues this and related ideas.

Within this theory, the rule of Guttural Lowering will be formulated as follows (I use "C" and "V" to stand for the Root nodes of consonants and vowels) :

(12) Arabic Guttural Lowering (Final Version)

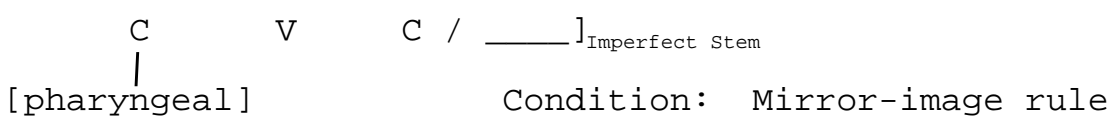

That is, [pharyngeal] spreads from any guttural to the adjacent thematic vowel, changing it to a. This is essentially the form of Guttural Lowering in Herzallah (1990), who further develops the analysis of this phenomenon in McCarthy (1989). This account raises further questions about the nature of vowel height distinctions, but we cannot pursue those here.

Two other examples of guttural lowering come from Tiberian Hebrew, one of the pronunciation traditions for Biblical Hebrew. There is a considerable literature on Hebrew phonology, including in particular Prince (1975), Malone (1984), and McCarthy (1979). The overall structure of the analysis is drawn from these works without special attribution; when a particular insight is important, though, I have attempted to note its source. ${ }^{12}$

One of the central problems in Hebrew phonology is the treatment of schwa. The Tiberian vocalization system represents four types of schwa: $\underline{a}-$

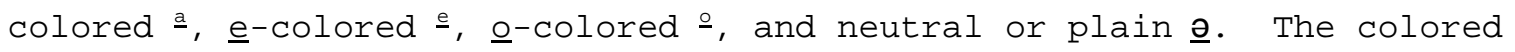
schwas are often associated with guttural contexts, and so they will be our focus below.

The rule of Vowel Reduction, which affects short unstressed vowels in open syllables, is a major source of schwas in the language. One of many places where Vowel Reduction occurs is the initial syllable of the plural 
nouns in (13a); compare the same syllable in the guttural-initial nouns of $(13 b):$

(13) Singular Plural

a. Plain-initial Nouns

\begin{tabular}{|c|c|c|}
\hline melek & məlākīm & 'king' \\
\hline qeber & qəbār̄̄m & 'grave' \\
\hline sēper & səpārīm & 'book' \\
\hline qōde & $\mathrm{q}^{\circ} \mathrm{d} \overline{\mathrm{a}} \int \overline{\mathrm{I}} \mathrm{m}$ & 'holine \\
\hline
\end{tabular}

b. Guttural-initial Nouns

\begin{tabular}{|c|c|c|}
\hline ?eben & $?^{a} \mathrm{~b} \overline{\mathrm{a}} \mathrm{n} \overline{\mathrm{I}}$ & 'stone' \\
\hline hebel & $h^{a} \mathrm{~b} \bar{a} l \bar{l} m$ & 'vapor' \\
\hline heder & $\hbar^{a} d \bar{a} r \bar{I} m$ & 'room' \\
\hline Sēder & $\Upsilon^{a} \mathrm{~d} \bar{a} r \bar{I} \mathrm{~m}$ & 'flock' \\
\hline ћōde & $\hbar^{\circ} \mathrm{d} \overline{\mathrm{a}} \int \overline{\mathrm{I}} \mathrm{m}$ & 'month' \\
\hline
\end{tabular}

Rounding of the stem vowel o persists under reduction, usually with an initial guttural and less regularly otherwise. Apart from that, the consistent picture is one where gutturals are followed by a-colored schwa, while non-gutturals are followed by plain schwa. This is a pervasive regularity of the language, so much so that plain schwa is never found after a guttural (in a search of the whole Pentateuch). Schwa before a guttural is not affected: compare the singular/plural pair $\underline{\mathrm{b} a\{a l} / \underline{\mathrm{b} \theta \Gamma \bar{a} l \bar{I} m}$ 'master'. ${ }^{13}$

A second source of schwas in Hebrew is epenthesis into unsyllabifiable consonant clusters. Hebrew has many surface CVCVC nouns with penult stress. Since penult stress is otherwise impossible in consonant-final words, these nouns are analyzed as underlying /CVCC/ with stress and epenthesis applied in that order. The epenthesis rule is responsible for alternations like the following: 
(14)

Underlying Singular

a. Plain Roots

/malk/ melek

/sipr/ sēper

/quds/ qōde]

b. Medial Guttural Roots

\begin{tabular}{|c|c|c|}
\hline /ba्l / & $\mathrm{ba} \underline{\underline{a}} 1$ & 'master' \\
\hline /kaћ// & kahaj & 'lying' \\
\hline /lahb/ & lahab & 'flame' \\
\hline /tu?r/ & to?ar & 'form/his form' \\
\hline
\end{tabular}

The boldface vowel in (14) is epenthetic, and from (14b) it is clear that

this vowel is lowered by a preceding guttural.

Prince (1975) and Garr (1989) argue that the epenthetic vowel in (14)

is actually schwa, so (14b) evidences the same guttural lowering rule as

(13). The argument for epenthesis of $\underline{\partial}$ rests on a central distributional

fact of Hebrew: the reduced vowels $\underline{\partial}, \underline{a}, \underline{e}$, and $\subseteq$ never occur in closed

syllables. This distributional evidence is supported by the alternation in $(15 a)$.

a.

/dabarl dābār dobar dibrēerd/word of/words of'

b.

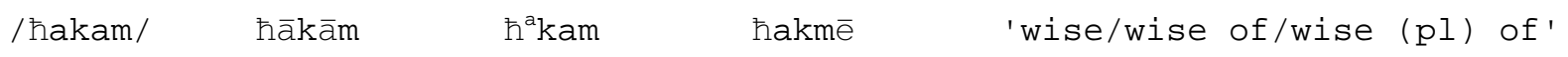

The intermediate representation dobərē loses the second of two adjacent schwas by a separate rule, yielding dobrē. The realization of schwa in this non-final closed syllable is $\underline{i}$. The choice between the e realization of schwa in melek and the $\underline{\text { i }}$ realization of schwa in dibre reflects a 
another general distributional fact of the language: i never occurs in closed final syllables and $\underline{e}$ never occurs in closed medial syllables. ${ }^{14}$

We can now return to the behavior of medial guttural roots in (14b). We know from the previous discussion that Hebrew has a rule lowering schwa to a after a guttural (13b). The epenthetic schwa of medial guttural roots like bafal (from /bafəl/) behaves in exactly that way. Its realization is the full vowel a rather than a the reduced vowel a for prosodic reasons -because the syllable is closed (compare (15b)). The rule of Guttural Lowering in Hebrew affects only a guttural-plus-schwa sequence in that order :

(16) Hebrew Guttural Lowering I

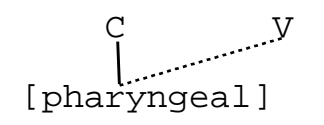

Condition: Feature-filling

The intent of the condition restricting (16) to feature-filling applications is to block the rule from lowering any vowel other than the featureless vowel schwa.

Hebrew has another rule of vowel lowering induced by gutturals, but in this case the guttural must follow the affected vowel. Nouns of the same type as (14) but with final gutturals are exemplified in (17):

\begin{tabular}{|c|c|c|c|}
\hline /zarl/ & zerâ & $\operatorname{zar}\lceil\bar{\imath}$ & 'seed/my seed' \\
\hline /mish/ & mēSah & misћō & 'brow/his brow' \\
\hline /Purh/ & ?ōraћ & 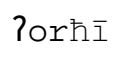 & 'way' \\
\hline /gubh / & gōbah & gobhō & 'height' \\
\hline
\end{tabular}

The boldface vowel in (17) has been lowered under the influence of the following guttural. Final $\underline{?}$ deletes after triggering epenthesis but before lowering: /pall/ -> pele 'wonder'.

Is this phenomenon an indication that (16) should be a mirror-image rule or is it the result of a distinct process? There are two arguments for the latter. First, lowering in final guttural words like zeraf must apply later in the derivation than lowering in medial guttural words like 
bafal. The reason has to do with the vowel of the first syllable, in both cases derived from underlying /a/. In zeraf, this vowel has umlauted to e , like melek, but unlike bafal. Therefore lowering in bafal must precede umlaut, but lowering in zeraf must follow umlaut (Malone 1984). Besides this difference in ordering, a more significant indication that pre-guttural lowering is a distinct rule from (16) is that preguttural lowering affects not only schwa, but any vowel before a tautosyllabic root-final guttural (Malone 1978):

Underlying Surface Compare

a.

/Samel/ Jāmal Jāmêr $\bar{u} \quad$ 'he heard/they heard'

/gaboh/ gəbah gəbōhīm 'high of/high (pl.)'

b.

/mōћ/ moa

/nōh/ noah

'marrow'
'eminency'

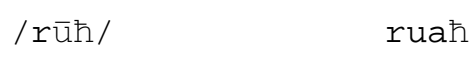

rū̄ī 'spirit/my spirit'

$/ \int \bar{u} S / \quad$ Juas

' cry'

/ T̄̄ /

Tiah

'coating'

/s'ameh/

s'àmeah

s'əmē̄inm 'glad/pl.'

There are sporadic examples of (18a) with etymologic * $\underline{r}$ as the trigger. Accepting Malone's interpretation of the orthography for (18b), we can see that any short vowel and the second mora of a long vowel are lowered by a following tautosyllabic guttural (stem-finally). This feature-changing process is clearly distinct from the feature-filling guttural assimilation rule (16), and so it requires a different formulation: 
(19) Hebrew Guttural Lowering II

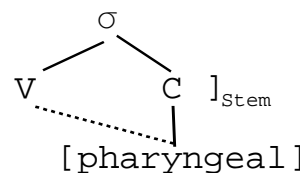

This rule affects an entire short vowel (18a) but only the second mora of a long vowel (18b).

In a completely separate historical development, Bedouin Arabic also has a fully productive rule lowering a vowel after a guttural consonant. This process is documented in treatments of various Bedouin dialects, including Johnstone (1967), Abboud (1979), Al-Mozainy (1981), Prochazka (1988), Irshied and Kenstowicz (1984), and Irshied (1984). The data here come from the 'Anaiza (Saudi Arabia) dialect described by Johnstone, who provides the most extensive exemplification.

This language has a pervasive rule of vowel raising, which applies to any short $\underline{\text { a }}$ in an open syllable:

(20) Raising

a $\rightarrow$ i / $\left.\mathrm{C}_{[}\right]_{\sigma}$

Raising is responsible for alternations in paradigms like the following:

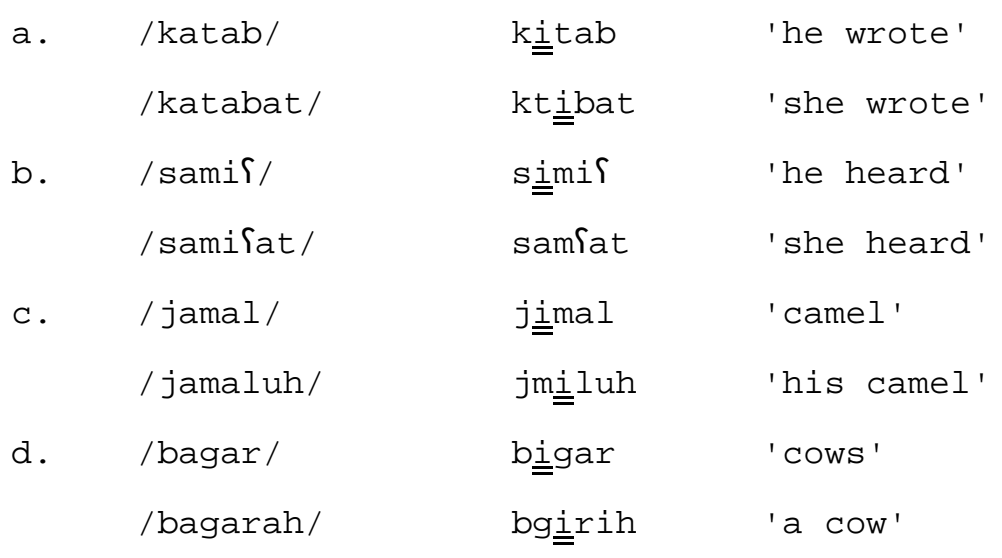

Since Bedouin Arabic has only a very limited distinction between short $\underline{\underline{1}}$ and $\underline{u}$, the output of Raising is quite variable and dependent on consonantal context, ranging from $\underline{u}$ or $\dot{i}$ in some labial contexts to $\dot{i}$ in emphatic contexts to i elsewhere. 
There are, however, various circumstances where Raising is systematically blocked or undone, so that a short a does occur in an open syllable. Of these, the relevant one is after a guttural:

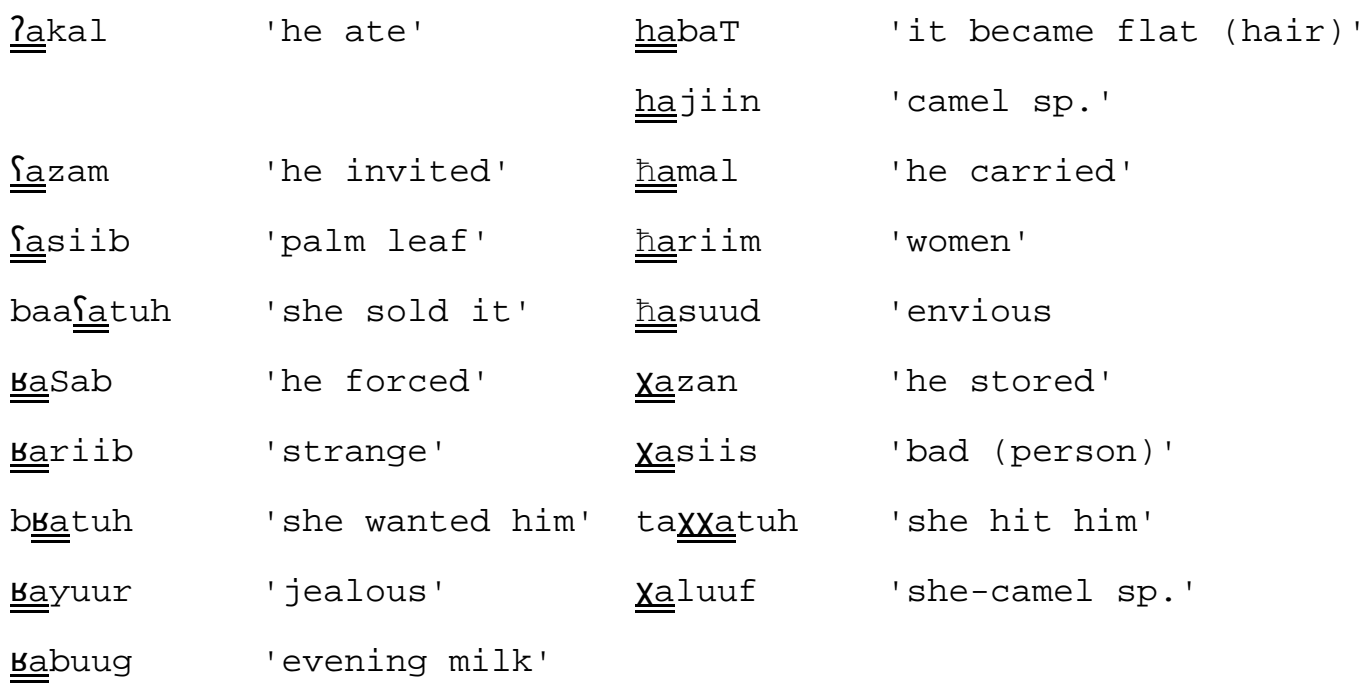

Vowels before short $\underline{i}$ are raised even when a guttural precedes (Bidib 'he got angry', 集if 'he became thirsty'), but this is caused by a different rule that is not our concern here. There is striking support for Raising and Guttural Lowering from a secret language that permutes the root consonants (Al-Mozainy 1981). In this secret language, Raising applies or not, exactly as expected:

$\begin{array}{ll}\text { Normal Form } & \text { Secret Language Forms } \\ \text { diffal 'he pushed' } & \text { fidal } \\ & \text { Sadaf }\end{array}$

Raising and Guttural Lowering are productive rules of the lexical phonology of Bedouin Arabic, applicable in secret language forms and in loans.

These various rules do not exhaust the Semitic evidence of a strong preference for low vowels in guttural contexts. For example, the epenthetic vowel in Lebanese Arabic (Haddad 1984: 46), normally $\underline{\underline{1}}$, is realized as a when adjacent to a guttural: balal 'swallowing', 近的 'poetry', jarah 'wounding'. Hayward and Hayward (1989) observe that in 
many Ethiopian Semitic languages (Tigrinya, Harari, Gafat, Amharic) the opposition between mid and low central vowel phonemes is neutralized to low when tautosyllabic with a guttural. Outside Semitic, a connection between low vowels and laryngeal or other guttural consonants has been observed in the Cushitic language D'opaasunte (Hayward and Hayward 1989), the Chadic language Kera (Odden 1988), the Athabaskan language Carrier (Prunet 1990), and the Tsimshian language Nisgha (Shaw 1987).

In sum, the material shows that, with respect to vowel lowering, all three guttural types -- uvular, pharyngeal, and laryngeal -- behave alike. The core result, of course, is that all these generalizations require that we identify the gutturals as a natural class.

\section{X.3.3 Avoidance of Syllable-final Gutturals}

An equally robust but somewhat more puzzling phenomenon is a prohibition on guttural codas. In a typical case, a CVGCV sequence, where G is a guttural, becomes CVGVCV by epenthesis, so that the guttural becomes the onset of a new syllable and is shifted out of coda position.

One case of this sort is found in various Bedouin Arabic dialects (Mitchell (1960), Johnstone (1967), Blanc (1970), Abboud (1979), Al-Mozainy (1981), Irshied (1984)). Blanc dubs it the gaháwah syndrome after the word 'coffee', an example of the phenomenon.

In Negev Bedouin Arabic (Blanc 1970), Ca GCVC, where G is a guttural, becomes CâGaCVC. Compare the plain and guttural roots in (24): 
(24)

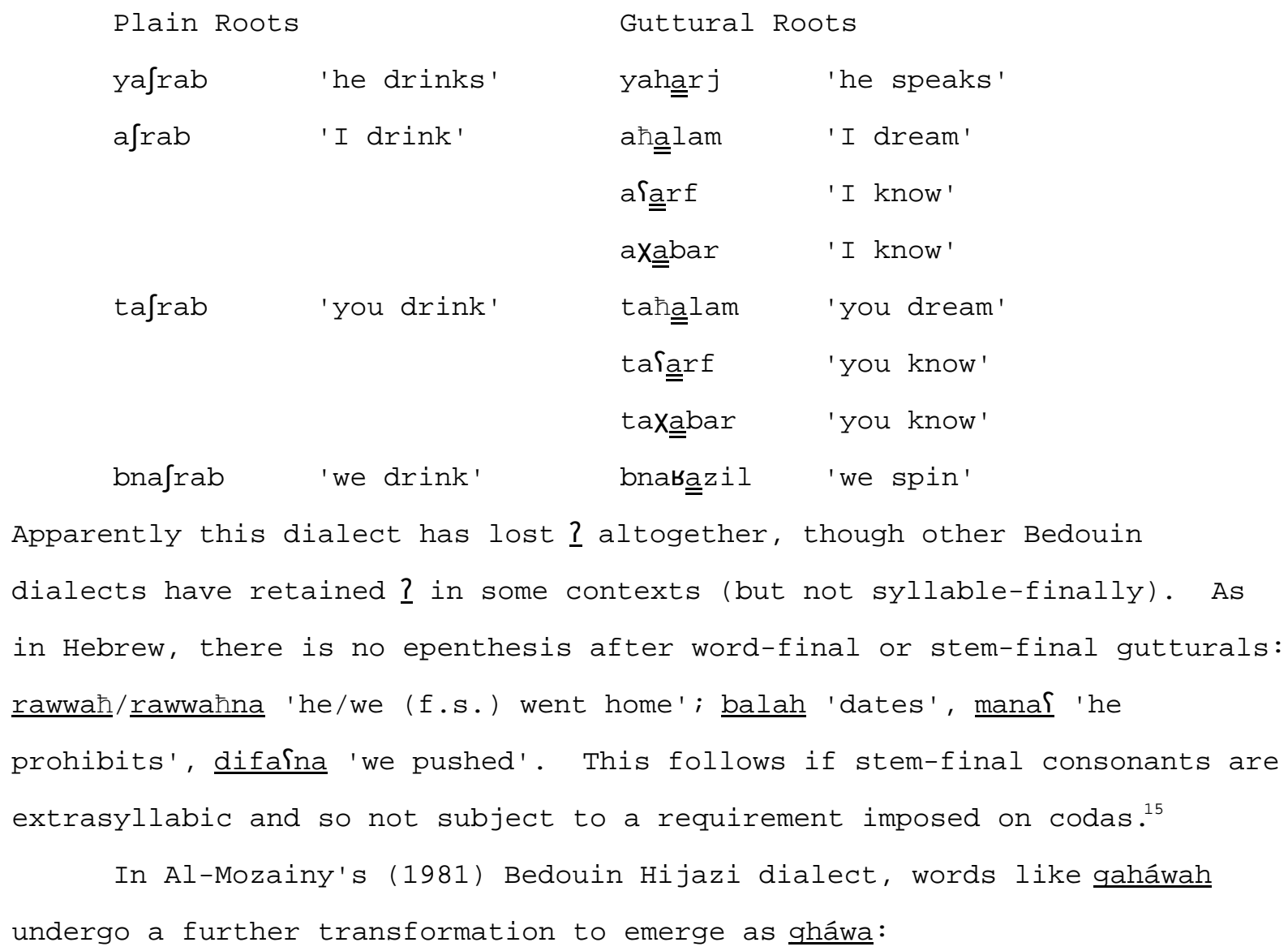


(25)

Plain Root

Color Adjectives

sawda 'black'

Verb Form $\mathrm{X}$

Pistaslam 'he surrendered'

Form I Passive Participle maktuub 'written'
Guttural Roots

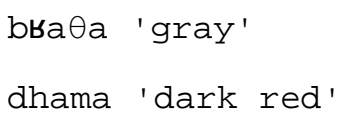

bвaөa 'gray'

dhama 'dark red'

Tist Tazal 'he got in a hurry'

Pisbafar 'he asked forgiveness'

Form I Imperfect

yajrab 'he drinks'

yxadim 'he serves'

yћakim 'he governs'

The Hijazi forms in (25) undergo an additional rule (called Elision by Irshied and Kenstowicz (1984), who provide a convincing rationale for it) that deletes $\underline{a}$ in a C CVCV context. Elision applies to the output of post-guttural epenthesis (Abboud 1979: 471; Al-Mozainy 1981: 172), so the derivation proceeds: /yaxdim/ -> /yaxadim/ $\rightarrow$ yxadim 'he serves'. ${ }^{16}$ Post-guttural epenthesis is restricted to syllables containing the vowel a. With syllables containing a high vowel preceding the guttural,

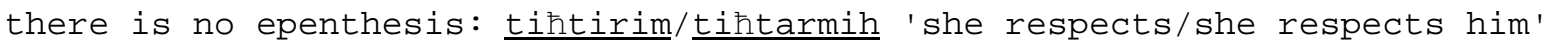
(Al-Mozainy 1981: 238). Thus, the descriptive generalization is that syllable-final gutturals are prohibited just in case the preceding vowel is a. Formally, we require a well-formedness condition something like the following: 
(26) Bedouin Arabic Syllabic Cooccurrence Condition

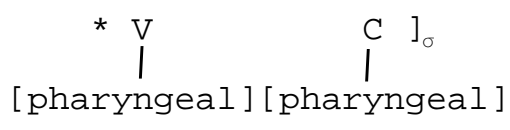

The condition on the preceding vowel is a kind of OCP-triggered dissimilation, prohibiting two [pharyngeal]s within the rhyme domain of the syllable. Like guttural lowering, this phenomenon shows both the need for a guttural class and a similarity between gutturals and low vowels.

Hebrew, though, prohibits guttural codas regardless of the preceding vowel, also resolving them by epenthesis:

a. Plain Roots

$\begin{array}{ll}\text { yiktōb } & \text { 'he will write' } \\ \text { hijmīd } & \text { 'he annihilated' } \\ \text { hujlak } & \text { 'he was thrown' }\end{array}$

b. Guttural Roots

\begin{tabular}{|c|c|}
\hline $\mathrm{ya}^{\mathrm{a}} \mathrm{mō} \mathrm{d}$ & 'he will stand' \\
\hline $\operatorname{yeh}^{\mathrm{e}} \mathrm{zaq}$ & 'he is strong' \\
\hline $\operatorname{yah}^{a} \mathrm{pōk}$ & 'he will turn' \\
\hline$y e ?^{e} s \bar{p} p$ & 'he will gather' \\
\hline$h e \int^{e} \operatorname{mi} d$ & 'he made stand' \\
\hline$h e \hbar^{e} z \bar{\imath} q$ & 'he strengthened' \\
\hline yo $\Upsilon^{\circ} \mathrm{mad}-$ & 'he is made to stand' \\
\hline
\end{tabular}

In some words $\underline{?}$ is lost syllable-finally, so epenthesis does not happen. The process is subject to exceptions and some other complications (cf. Malone (1984:94)).

The quality of the inserted schwa in (27b) is obviously determined by the quality of the preceding vowel; I deal with this matter elsewhere (McCarthy forthcoming). The fact that a schwa rather than a full vowel is inserted is typical of Hebrew (see section X.3.2). Therefore, the only real issue is that of prohibiting syllable-final gutturals, which we can accomplish by the following coda condition (cf. Itô (1986, 1989)): 
(28) Hebrew Coda Condition

\author{
$\star \mathrm{C}]_{\sigma}$ \\ | \\ [pharyngeal]
}

This constraint simply marks as ill-formed any syllable with a guttural coda. Epenthesis repairs violations of the Coda Condition (28) by inserting schwa, which then harmonizes with the preceding vowel across the intervening guttural. The coda Condition does not affect word-final or

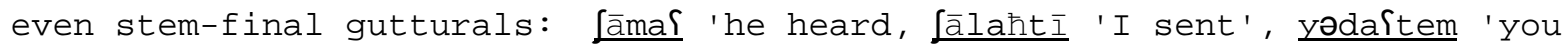

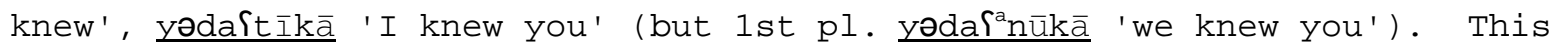
follows, as in Bedouin Arabic, if we suppose that stem-final consonants are extrasyllabic and hence not subject to the Coda Condition.

An examination of Tigre (Ethiopian Semitic) verb paradigms shows virtually the same rule in that language:

Plain Roots

toqnas 'you get up'

qansa

qanasko

ləqanSo 'he got up'

' I got up'

'they get up'
Guttural Roots

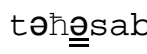

Sạana

bal $\underline{\underline{a}}$ ko

ləS $\{\underline{\underline{a}}$ no 'you wash'

'he loaded'

' I ate'

'they load'

The Tigre gutturals are the same as those of Hebrew (but see section X.5). In the published material on Tigre (Leslau 1945, Palmer 1956, 1962, Raz 1983), I have not located a plain statement of the generality of this phenomenon or the further deletion in the second two examples. Nevertheless, it seems quite clear that there is a process inserting a copy of the preceding vowel after any syllable-final (but not word-final) guttural.

To sum up, the class of gutturals, defined by the feature [pharyngeal], is required to characterize the consonants prohibited in stem-medial coda position in Hebrew and Tigre. Bedouin Arabic also prohibits gutturals in the coda, but only after a low vowel, perhaps as a kind of dissimilation. 


\section{X.3.4 Guttural Degemination}

Hebrew and Tigre also exhibit a prohibition on geminate gutturals, a phenomenon that is perhaps to be related to (28). In Hebrew, geminate gutturals are simplified without exception. This is clear from a comparison of plain and guttural roots in examples like the following:

Plain Root

dibbēr

/yintē/ -> yittēn 'he gives'

dallim 'weak ones'
Guttural Roots

mēēen 'he refused'

/yinhat/ -> yēhat 'he marches down '

'evil ones'

Discussions of this phenomenon appear in Prince (1975:219f.), Malone (1978, 1984:79), and Lowenstamm and Kaye (1986). Guttural degemination itself is straightforward, though the compensatory lengthening seen in the cited examples does not always occur (cf. Prince 1975)..$^{7}$

Likewise in Tigre (Leslau 1945, Palmer 1956, 1962, Raz 1983),

gutturals are degeminated. Compare the following plain and guttural roots:

\begin{tabular}{|c|c|c|c|}
\hline təqarrača & 'he was cut off' & təoba?asa & 'he quarreled' \\
\hline LəqannəS & 'he gets up' & ləSโən & 'he loads' \\
\hline
\end{tabular}

Raz and Leslau describe dialects where the high glides $\underline{w}$ and $\underline{y}$ are also degeminated, but this is not true in Palmer's material. Thus, it seems appropriate to see the degemination of gutturals and of high glides as two separate generalizations.

It is straightforward to write a rule simplifying geminate gutturals or prohibiting their creation. Something like the following would do and would accord with the fact that languages frequently impose conditions on which geminates are licit. 
(32) Guttural Degemination

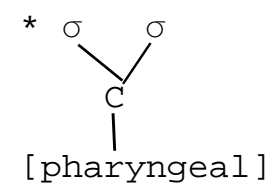

Violations of this constraint are repaired in the most straightforward way, by delinking and compensatory lengthening.

Guttural Degemination may be related to the Coda Condition in both Hebrew and Tigre. If gutturals are prohibited in syllable codas, then they cannot be geminated either, since the left branch of a geminate is necessarily a coda. Although this move is appealing, it does lead to a significant conflict with Itô's (1986) results about the applicability of the Linking Condition (Hayes 1986) to coda conditions like (28). Itô shows that geminates constitute a systematic exception to coda conditions in other languages. Until this conflict is resolved, Guttural Degemination and the Coda Condition should be regarded as separate pieces of evidence for the natural class of gutturals.

\section{X.3.5 Interim Summary}

The evidence presented establishes the existence of a natural class of gutturals and thus provides direct support for the claims about the feature [pharyngeal]. The evidence meets the various criteria established at the outset. First, it involves robust, well-attested phenomena that come from historically independent innovations of different languages within the semitic family. Second, the evidence is entirely synchronic rather than historical. Third, the evidence comes from several different types of processes: root cooccurrence restrictions, vowel lowering, and conditions on syllable position and gemination. Fourth, the evidence comes from all levels of representation, not just deep morphophonemics and not just the surface. 
X.4 Pharyngeals and Pharyngealization

Thus far we have discussed only the guttural consonants. The goal of this section is to provide some initial suggestions about how to integrate the pharyngealized sounds -- the coronal emphatics and $\underline{q}$-- into the analysis. The phonetic and phonological evidence shows that the pharyngealized consonants share the feature [pharyngeal] with gutturals, although they also have a primary oral articulation.

In addition to the gutturals, the semitic languages have a class of sounds called emphatics, with what is traditionally regarded as a secondary pharyngeal constriction. In standard Arabic, the emphatics include the coronal fricatives $\underline{S}$ and $\underline{Z}$ (the latter often interdental), the coronal stops $\underline{T}$ and $\underline{D}$, and the uvular stop $\underline{q}$. The coronals contrast with corresponding nonemphatics $\underline{s}, \underline{z} / \underline{\partial}, \underline{t}$, and $\underline{d}$, while $\underline{q}$ contrasts with the velar stop $\underline{k}$. Other Semitic languages have a subset of the Standard Arabic emphatics, and in South Semitic languages like Tigre the emphatics are realized phonetically as ejectives.

Ghazeli's (1977) x-ray study deals with the emphatics of Tunisian Arabic in great detail. His observations about the coronal emphatics are confirmed elsewhere in the literature (by Ali and Daniloff (1972), Al-Ani (1970), and Bukshaisha (1985)), and his observations about the uvular stop q are confirmed by Delattre (1971). Despite differences in details, the overall picture is consistent: the emphatics and $q$ have a constriction in the upper pharynx similar to that of the uvular gutturals $\mathbf{X}$ and $\underline{\mathbf{k}}$. Although there are suggestions (Keating 1988) that Arabic dialects differ in the location of the secondary constriction of emphatics (with some showing a low, -like constriction), this does not seem to be true; all studies, now encompassing several different dialect areas, find that the emphatics have a constriction in the upper pharynx. The so-called pharyngealized consonants of Arabic should really be called uvularized.

The phonetic evidence establishes important points of similarity between the gutturals and the emphatics. Broadly, the gutturals and the 
emphatics share constriction in the pharynx, and narrowly, the uvular gutturals share with $\underline{q}$ and the coronal emphatics a constriction in the oropharynx produced by raising and retracting the tongue body. We expect to find two principal types of phonological patterning corresponding to these phonetic resemblances: a class of primary and secondary [pharyngeal]

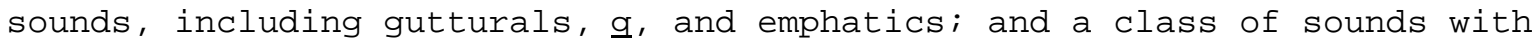
[pharyngeal] constriction produced by the [dorsal] articulator, including uvular gutturals, $\underline{\mathrm{q}}$, and emphatics.

A striking example of the first type of phonological patterning comes from Herzallah's (1990) analysis of 'imāla (raising/fronting) of the feminine suffix. In many Eastern Arabic dialects, the feminine suffix, historically - $\underline{\text { a }}$ appears as -e or - $\underline{\underline{i}}$ except when preceded by a [pharyngeal] consonant. The following data come from Syrian Arabic (Cowell 1964: 138, Grotzfeld 1965: 45):

\begin{tabular}{|c|c|c|c|c|}
\hline \multirow[t]{3}{*}{ a. } & daraže & 'step' & kbīre & 'large' \\
\hline & madrase & 'school' & Jərke & 'society' \\
\hline & Xafife & 'light' & & \\
\hline \multirow[t]{5}{*}{$\mathrm{b}$. } & TəSSa & 'story' & SarīDa & 'broad' \\
\hline & хауyа̄Ta & 'seamstress' & bāyza & 'foul' \\
\hline & TabXa & 'cooking' & daggāıа & 'tanning' \\
\hline & mnīha & 'good' & wāžha & 'display' \\
\hline & $\operatorname{San}\{a$ & 'handwork' & xər?a & 'rag' \\
\hline
\end{tabular}

In dialects that have retained $\underline{q}$, it too patterns with the consonants in (33b), as does $\underline{r}$ when it is emphatic. Some dialects distribute the allomorphs of this suffix according to different principles and some have 'imāla everywhere, but the pattern in (33) is probably the most widespread. The synchronic underlying representation of the the feminine suffix is a non-low vowel e or $\underline{i}$, with the examples in (33b) derived by lowering this vowel to a after any [pharyngeal] consonant. This lowering rule can be stated as follows, essentially following Herzallah (1990: 138): 
(34) Feminine Suffix Lowering

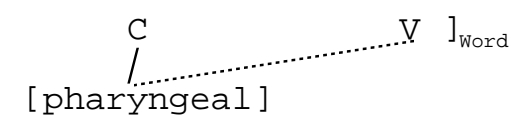

This process is similar to Guttural Lowering (section x.3.2), but it is triggered by any [pharyngeal] consonant, not just a guttural.

Other evidence of the emphatic/guttural connection comes from historical changes in which an emphatic lost its primary place of articulation to become a guttural. Two independent historical changes of this sort have occurred in Semitic (Blake 1946, 214). First, some Ugaritic words have $\underline{\mathbf{b}}$ for original $\underline{\mathrm{z}}$ : compare Arabic nzr with Ugaritic nur 'guard'. Second, original D became $\underline{f}$ in Aramaic: compare Arabic $\underline{\text { TarD }}$ with Aramaic

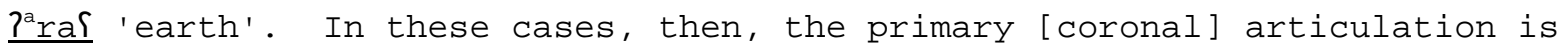
lost, thereby promoting the secondary [pharyngeal] one. The parallel to sound changes like ${ }^{*} \underline{k^{w}}>\underline{p}$ in the history of Greek is obvious. ${ }^{18}$

The other phonological class expected on phonetic grounds is defined by oropharyngeal constriction -- that is, consonants that are both [dorsal] and [pharyngeal], including the emphatics $(\underline{S}, \underline{Z}, \underline{T}$, and $\underline{D})$ and the uvulars $(\underline{q}, \mathbf{X}$, and $\underline{b})$. Since the definition of this class requires reference to the redundant [dorsal] specification of the coronal emphatics, it should only be relevant in relatively late rules, after default [dorsal] has been filled in. That seems to be the case.

This class plays a role in the complex phenomenon of backing or emphasis spread in Arabic. Perhaps the earliest description of this comes from Sībawayhi (quoted in Younes (1982, 82)): "The back variant [of a ] occurs, that is the low vowel is not fronted, when it derives from underlying $\underline{\mathrm{w}}$ (or $\underline{\mathrm{uu}}$ ) and when immediately preceded or followed by one of the following consonants: $\underline{S}, \underline{Z}, \underline{T}, \underline{D}, \underline{b}, \underline{X}, \underline{\boldsymbol{q}}$, and $\underline{r} . "$ Since $\underline{r}$ is contextually emphatic, in our terms this is the class of dorso-pharyngeals. Herzallah (1990: 181) describes a similar process in Palestinian Arabic, which derives the imperfect theme vowel u from $\underline{i}$ adjacent to a coronal emphatic or uvular, as spreading of [dorsal]. But there are many 
additional complications and a full discussion of emphasis spread in Arabic dialects would require a monograph rather than these few lines.

Another phonological class we would expect to find on phonetic grounds is the set of underlying [dorsal] consonants: the velars and uvulars $\underline{k}, \underline{\underline{g}}, \underline{\mathbf{q}}, \mathbf{X}$, and $\underline{\boldsymbol{k}}$. In Moroccan Arabic (Ahmed Alaoui p. c. and Heath 1987: 254), consonant labialization, realized as rounding on a following schwa, is restricted to the dorsals. The following imperative verbs exemplify this:

(35) Moroccan Labialization

\begin{tabular}{|c|c|}
\hline$d x^{W} \partial 1$ & 'come in!' \\
\hline$n B^{w} \partial z$ & 'prick!' \\
\hline$n q^{\text {W}} \partial 1$ & 'copy down!' \\
\hline$r g^{w} \partial d$ & 'sleep!' \\
\hline$n k^{w} \partial r$ & 'deny!' \\
\hline
\end{tabular}

Labialization is not permitted with other consonants, oral or guttural: ktəb) 'write!', nโəs 'sleep!'. Formally, this means that the marking conditions that describe the Moroccan Arabic consonants system must contain a statement like [+round] $\rightarrow$ [dorsal].

Even more striking evidence for the underlying [dorsal] class comes from an additional property of the system of root cooccurrence restrictions in Arabic. Recall from section X.3.1 that Arabic prohibits (with exceptions) roots containing two consonants from the set $\{\underline{q}, \underline{k}, \underline{q}\}$ and roots containing two consonants from the set $\{\underline{X}, \underline{\mathbf{b}}, \underline{\hbar}, \underline{\mathbf{I}}, \underline{\mathrm{h}}, \underline{\boldsymbol{l}}\}$. The first set is actually incomplete, though; it should include the uvular gutturals $\mathbf{X}$ and $\underline{\mathbf{b}}$ as well. This patterning of the uvular continuants with both the gutturals and the dorsals is apparent from the statistical evidence in (5). This final observation about the dual patterning of $\boldsymbol{X}$ and $\underline{\mathbf{b}}$ in the system of root cooccurrence restrictions provides the strongest indication that the uvular gutturals are complex segments, bearing simultaneous specifications for [dorsal] and [pharyngeal]. The coronal emphatics and $\underline{9}$ are also complex segments, with both oral and pharyngeal articulations. 
Under standard feature-geometry assumptions (Clements 1985, Sagey 1986, McCarthy 1988), the various types of consonants are represented approximately as follows:

a. Low Gutturals $\underline{\text { h hhS }}$

$$
\text { [pharyngeal] }
$$

c. Coronal Emphatics TDSZ

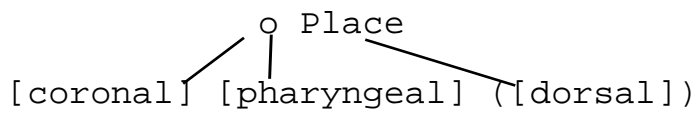

b. Uvular Gutturals $\mathbf{X B}$

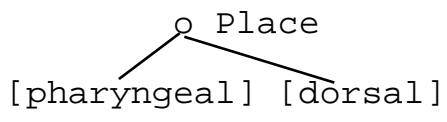

d. Uvular stop $\underline{\text { q }}$

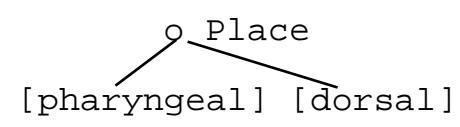

Here, the redundant [dorsal] specification of the coronal emphatics is parenthesized to indicate that it is not present in underlying representation.

This proposal resolves the issue of phonetic and phonological connections between emphatics and gutturals, but it raises another question of how to tell them apart phonologically. In particular, how is the true guttural class referred to in the rules developed in section X.3, and how are the uvular gutturals distinguished from the uvular stop ${ }^{19}$

Although more elaborate accounts based on the distinction between primary and secondary articulations are possible and may be correct (McCarthy 1991b, Herzallah 1990), the most straightforward answer to these questions relies on the observation, noted originally in section X.2.1, that the gutturals are approximants but the emphatics and $q$ are not. Thus, the guttural class is defined by the conjunction of the place feature [pharyngeal] and the major class feature [approximant]. This makes good sense of the evidence for the guttural class: the root cooccurrence restrictions are known independently to refer to another major class feature, [sonorant], to distinguish between the coronal sonorants and obstruents; guttural lowering is typical of the robust effect that approximants have on the quality of adjacent vowels; and rules specifying possible codas or geminates must often refer to major class features. The 
proposal in (36), then, makes the necessary distinctions while also defining the right natural classes of guttural and pharyngealized consonants.

\section{5 Conclusion}

The major observation of this paper is that the gutturals of Semitic constitute a natural class. The major thesis is that sounds are classified by place of articulation as well as articulator. In particular, there is a [pharyngeal] place of articulation, referring to the region from oropharynx to larynx inclusive. Furthermore, I have argued that this region in the articulatory space makes sense under Perkell's (1980) characterization of features as "orosensory targets", given what is known about the different distribution of sensory nerves in the vocal tract.

The principal source of evidence for this claim is the synchronic phonology of the Semitic languages, with occasional forays into diachrony and Afro-asiatic. I have comprehensively treated the recurrent phonological phenomena of semitic involving the gutturals. I have also extended the results in a less comprehensive way to the pharyngealized consonants.

It is customary to conclude a work like this by raising questions for further research. There are many, but two are particularly pressing. The first involves the locus of [pharyngeal] in an overall model of feature geometry along the lines of Clements (1985), Sagey (1986), and McCarthy (1988). Because of space limitations, I can only sketch the answer to that question here. In McCarthy (forthcoming), I argue that there is a division between Oral and [pharyngeal] place of articulation features: 
- Root Node

○ Laryngeal Node

- Place Node

[voice][const] [spread] O Oral

[lab] [cor] [dors] [pharyngeal]

The claim is that [pharyngeal] can but need not pattern phonologically with the other place features [labial], [coronal], and [dorsal].

From a phonetic point of view, this model is quite plausible. The feature [pharyngeal] is defined in terms of a region of the vocal tract (the pharynx) and a particular spectral property (high F1), two characteristics that are basically what we expect of Place features. At the same time, this model makes sense of the asymmetry (noted in section X.2.3) between the anterior part of the vocal tract, which is organized in terms of active articulator, and the posterior part, which is organized in terms of place of articulation.

Phonological evidence for (37) comes principally from two partly conflicting descriptive requirements. On the one hand, the system of root cooccurrence restrictions in semitic (section X.3.1), which is based on prohibiting two homorganic consonants within a root, treats [pharyngeal] exactly on a par with the other Place features [labial], [coronal], and [dorsal]. On the other hand, there is a class of vowel-vowel assimilation rules, documented in McCarthy (forthcoming), to which Oral consonants are opaque and [pharyngeal] ones are transparent. In connection with other assumptions about transparency effects (Steriade 1987), this evidence shows the need for a separation between [pharyngeal] and the oral place features. A very different sort of question concerns the laryngeals $\underline{?}$ and $\underline{h}$. Although their behavior as part of the guttural class securely establishes that they have a place of articulation in many semitic languages, the laryngeals have usually been regarded as place-less within recent phonological work (Clements 1985, Sagey 1986, Hayes 1986, Steriade 1987). This ambiguity in the treatment of laryngeal consonants is not a special problem of Semitic. Hayward and Hayward (1989: 186) comment on it, and 
witness Catford (1977: 104) in a discussion of glottal stops: "complete closure of the glottis has either an initiatory or an articulatory function: the former in phonationless glottalic initiation and the latter in glottal stop as an articulatory type functionally parallel in languages to other kinds of stop articulation." Merlingen (1977: 205-6) finds even more types of $\underline{h}$ based on phonological patterning, though not all of the evidence is persuasive.

Even within Semitic, there is one compelling case where the laryngeals $\underline{?}$ and $\underline{h}$ do not pattern as gutturals. In Tigre (Leslau 1945: 1557; Raz 1983:5), $\underline{?}$ and $\underline{I}$ are in free variation in words that contain an

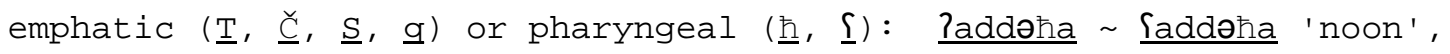

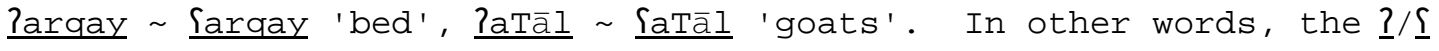
distinction is neutralized in a context that includes true pharyngeals and emphatics but not laryngeals. (Tigre has no uvular gutturals.) The most natural interpretation of this process is spreading of [pharyngeal] to , changing it to $\underline{\underline{I}}$. But of course this requires that $\underline{?}$ not be [pharyngeal] to start with. ${ }^{20}$

Further evidence from Tigre supports this view. The vowels $\geq$ and $\underline{a}$ are in complementary distribution: $\underline{a}$ is always followed or immediately preceded by an emphatic or a true pharyngeal (but not a laryngeal), while $\geq$ never occurs in that context (Palmer 1956: 569; Lowenstamm and Prunet 1989) :

\begin{tabular}{|c|c|c|}
\hline \multirow[t]{3}{*}{ a. } & fənat & 'haversack' \\
\hline & warəq & 'gold' \\
\hline & faral & 'clan' \\
\hline & warəћ & 'month' \\
\hline $\mathrm{b}$. & $f>r>s$ & 'horse' \\
\hline & $j>h>t$ & 'direction \\
\hline
\end{tabular}

Lowenstamm and Prunet analyze this as a case of vowel lowering in the context of a [pharyngeal] consonant (therefore comparable to (34) above). 
But this analysis presupposes that Tigre $\underline{?}$ and $\underline{h}$ are not [pharyngeal] (cf. $j>h>t$ in (38b)). Moreover, the rules referring to the guttural class in Tigre -- prohibitions on syllable-final and geminate gutturals (sections X.3.3 and X.3.4) -- can be recast as positive conditions requiring codas and geminates to have the oral node of (37) rather than as negative conditions referring to the class of gutturals.

It seems, then, that the laryngeal consonants of Arabic and Tigre are different phonologically: in the former, but not the latter, the laryngeals are specified as [pharyngeal] and so belong to the guttural class. It is, of course, easy to set up such a phonological distinction but quite hard to find a phonetic basis for it. The most attractive proposal is Hess's (1990) suggestion that Arabic $\underline{?}$ is actually not a true glottal stop at all, but an aryepiglottic one. Hess finds support for this conjecture in one $x^{-}$ ray of $?$ (from Boff Dkhissi (1983)) which shows an apparently protruding epiglottis. But there are several problems with this claim. First, as Hess notes, the position of the epiglottis in this token of $\underline{?}$ might just be its resting state for this particular speaker. Second, the context salala 'he asked', evidently a Standard Arabic word being read by a Moroccan Arabic speaker) could show pharyngeal constriction simply because of coarticulatory influence from the adjoining low vowels. Third, aryepiglottic place should perturb the formants of adjacent vowels, but no such perturbation by $\underline{?}$ has been observed. So we as yet have no evidence for a special phonetic treatment of Arabic ?.

We have seen evidence for the class of guttural consonants and how that class can be accounted for phonetically. We have also seen some of the phonological connections between the gutturals and emphatics and how those connections find phonetic support. These observations encourage us in the view that phonological classes always have a phonetic basis. But the difference between Arabic and Tigre laryngeals, phonologically important but phonetically invisible, may have show us a limit in our 
understanding of the relation between phonetic events and phonological features. 


\section{$\underline{\text { References }}$}

Abboud, Peter. 1979. 'The Verb in Northern Najdi Arabic', Bulletin of the School of Oriental and African Studies, University of London 42 : $467-499$

Al-Ani, Salman. 1970. Arabic Phonology. The Hague: Mouton. Al-Ani, Salman. 1978. 'An Acoustical and Physiological Investigation on the Arabic /9/', in Salman Al-Ani, (ed.), Readings in Arabic Linguistics. Bloomington: Indiana University Linguistics Club, pp. 89-101.

Al-Mozainy, Hamza Q. 1981. Vowel Alternations in a Bedouin Hijazi Arabic Dialect: Abstractness and Stress. Doctoral dissertation, University of Texas, Austin.

Ali, Latif and Daniloff, R. G. 1972. 'A Contrastive Cinefluorographic Investigation of the Articulation of Emphatic-Non Emphatic Cognate Consonants', Studia Linguistica 26: 81-105.

Alwan, Abeer. 1986. Acoustic and Perceptual Correlates of Uvular and Pharyngeal Consonants. MA thesis, MIT Dept. of Electrical Engineering and Computer Science.

Anderson, Stephen. 1971. 'On the Description of 'Apicalized' Consonants', Linguistic Inquiry 2: 103-107.

Bender, M. Lionel and Hailu Fulass. 1978. Amharic Verb Morphology. East Lansing, Michigan: African Studies Center, Michigan State University.

Blake, Frank R. 1946. 'Studies in Semitic Grammar IV', Journal of the American Oriental Society 66: 212-218.

Blanc, H. 1970. 'The Arabic Dialect of the Negev Bedouins', Proceedings of the Israel Academy of Sciences and Humanities 4: 112-150.

Boff Dkhissi, M.-C. 1983. 'Contribution à l'étude expérimentale des consonnes d'arrière de l'arabe classique (locuteurs marocains)', Trav. Inst. Phon. Strasbourg 15. [Not seen. Cited in Butcher and Ahmad. 1987]

Bukshaisha, Fouzia. 1985. An Experimental Study of Some Aspects of Qatari Arabic. Doctoral dissertation, University of Edinburgh. 
Butcher, Andrew and Ahmad, Kusay. 1987. 'Some Acoustic and Aerodynamic Characteristics of Pharyngeal Consonants in Iraqi Arabic', Phonetica $44: 156-172$.

Catford, J. C. 1977. Fundamental Problems in Phonetics. Edinburgh: Edinburgh University Press.

Catford, J. C. 1983. 'Pharyngeal and Laryngeal Sounds in Caucasian Languages', in Bless Diane M. and Abbs, James H. (eds.), Vocal Fold Physiology: Contemporary Research and Clinical Issues. San Diego: College-Hill Press.

Chomsky, Noam and Halle, Morris. 1968. The Sound Pattern of English. New York: Harper and Row.

Clements, G. N. 1985. 'The Geometry of Phonological Features', Phonology Yearbook 2: 223-250.

Clements, G. N. 1990. 'The Role of the Sonority Cycle in Core Syllabification', in Kingston, J. and Beckman, M. (eds.), Papers in Laboratory Phonology I: Between the Grammar and the Physics of Speech. Cambridge: Cambridge University Press, pp. 283-333.

Colarusso, John. 1985. 'Pharyngeals and Pharyngealization', International Journal of American Linguistics 51: 366-368.

Colarusso, John. 1988. The Northwest Caucasian Languages, a Phonological Survey. New York: Garland.

Cole, Jennifer. 1987. Planar Phonology and Morphology. Doctoral dissertation, MIT, Cambridge, MA.

Cowell, Mark W. 1964. A Reference Grammar of Syrian Arabic. Washington, DC: Georgetown University Press.

Delattre, Pierre. 1971. 'Pharyngeal Features in the Consonants of Arabic, German, Spanish, French, and American English', Phonetica 23: $129-155$

Dresher. B. Elan. 1989. 'Comments on "Guttural Phonology" [McCarthy (1989)]', paper presented at MIT Conference on Feature Geometry. 
El-Halees, Yousef. 1985. 'The Role of F1 in the Place-of-Articulation Distinction in Arabic', Phonetica 13: 287-298.

Elorrieta, Jabier. 1991. 'The Feature Specification of Uvulars', ms., University of Texas, Austin.

Garr, W. Randall. 1989. 'The Seghol and Segholation in Hebrew', Journal of Near Eastern Studies 48: 109-116.

Ghazeli, Salem. 1977. Back Consonants and Backing Coarticulation in Arabic. unpublished Doctoral dissertation, University of Texas, Austin.

Gesenius, W. 1910. Gesenius' Hebrew Grammar as Edited and Enlarged by the Late E. Kautzsch, Oxford: Oxford University Press.

Goldsmith, John. 1976. Autosegmental Phonology. Doctoral dissertation, MIT, Cambridge, MA.

Gorecka, Alicja. 1989. Phonology of Articulation. Doctoral dissertation, MIT, Cambridge, MA.

Greenberg, Joseph. 1950. 'The Patterning of Root Morphemes in Semitic', Word 6: 162-181.

Grossman, Richard C. 1964. 'Sensory Innervation of the Oral Mucosae', Journal of the Southern California State Dental Association 32: $128-133$

Grotzfeld, Heinz. 1965. Syrisch-Arabische Grammatik. Wiesbaden: Otto Harrassowitz.

Haddad, Ghassan F. 1984. 'Epenthesis and Sonority in Lebanese Arabic', Studies in the Linguistic Sciences 14: 57-88.

Halle, Morris. 1983. 'On Distinctive Features and their Articulatory Implementation', Natural Language and Linguistic Theory 1: 91-106.

Halle, Morris. 1988. 'The Immanent Form of Phonemes', in Hurst, W. (ed.), Giving Birth to Cognitive Science: A Festschrift for George A. Miller. Cambridge: Cambridge University Press. Halle, Morris and Stevens, Kenneth N. 1969. 'On the Feature 'Advanced Tongue Root', MIT Research Laboratory of Electronics Quarterly Progress Report 94: 209-215. 
Hayes, Bruce. 1986. 'Inalterability in CV Phonology', Language 62: 321-352. Hayward, R. J. 1989. 'Comparative Notes on the Language of the S'aamakko', Journal of Afroasiatic Languages 2: 1-53.

Hayward, K. M. and Hayward, R. J. 1989. '"Guttural": Arguments for a New Distinctive Feature', Transactions of the Philological Society 87 : $179-193$

Heath, Jeffrey. 1987. Ablaut and Ambiguity: Phonology of a Moroccan Arabic Dialect. Albany, NY: State University of New York Press.

Herzallah, Rukayyah. 1990. Aspects of Palestinian Arabic Phonology: A Nonlinear Approach. Doctoral dissertation, Cornell University, Ithaca, NY.

Hess, Susan. 1990. 'Pharyngeal Articulations in Akan and Arabic', ms., University of California, Los Angeles.

Hoberman, Robert. 1985. 'The Phonology of Pharyngeals and Pharyngealization in Pre-Modern Aramaic', Journal of the American Oriental Society 105: $221-231$

Hoberman, Robert. 1989. 'Parameters of Emphasis: Autosegmental Analyses of Pharyngealization in Four Languages', Journal of Afroasiatic Languages 2: 73-97.

van der Hulst, Harry. 1988. 'The Geometry of Vocalic Features', in van der Hulst, Harry and Smith, Norval. (eds.), Features, Segmental Structure, and Harmony Processes. Dordrecht: Foris.

Irshied, Omar. 1984. The Phonology of Bani-Hassan Arabic, a Bedouin Dialect, Doctoral dissertation, University of Illinois, ChampaignUrbana .

Irshied, Omar and Kenstowicz, Michael. 1984. 'Some Phonological Rules of Bani-Hassan Arabic: A Bedouin Dialect', Studies in the Linguistic Sciences $14: 109-147$.

Itô, Junko. 1986. Syllable Theory in Prosodic Phonology. Doctoral dissertation, University of Massachusetts, Amherst. 
Itô, Junko. 1989. 'A Prosodic Theory of Epenthesis', Natural Language and Linguistic Theory 7: 217-260.

Jackson, Michel. 1988. 'Analysis of Tongue Positions: Language-specific and Cross-linguistic Models', Journal of the Acoustical Society of America $84: 124-143$.

Jakobson, R., Fant, C. G. M., and Halle, M. 1963. Preliminaries to Speech Analysis. Cambridge, Mass: MIT Press.

Jakobson, Roman. 1957. 'Mufaxxama, the 'Emphatic' Phonemes of Arabic', Studies Presented to Joshua Whatmough on his 60 th Birthday. The Hague: Mouton.

Johnstone, T. M. 1967. Eastern Arabian Dialect Studies. Oxford: Oxford University Press.

Kahn, Margaret. 1976. 'How Abstract is Pharyngology: Evidence from Kurmanji', Papers from the Twelfth Regional Meeting Chicago Linguistic Society. Chicago: Chicago Linguistic Society.

Keating, Patricia A. 1988. A Survey of Phonological Features. Bloomington: Indiana University Linguistics Club.

Kenstowicz, Michael and Kisseberth, Charles. 1979. Generative Phonology. New York: Academic Press.

Kinkade, M. Dale. 1967. 'Uvular-Pharyngeal Resononants in Interior Salish', International Journal of American Linguistics 33: 228-234.

Kiparsky, Paul. 1974. 'A Note on the Vowel Features', in Kaisse, Ellen and Hankamer, Jorge (eds.), Papers from the Fifth Annual Meeting, North Eastern Linguistics Society. Cambridge, Mass.: Dept. of Linguistics, Harvard University.

Klatt, Dennis H., and Stevens, Kenneth N. 1969. 'Pharyngeal Consonants', MIT Research Laboratory of Electronics Quarterly Progress Report 93: $208-216$.

Koskinen, Kalevi. 1964. 'Kompatibilität in den dreikonsonantigen hebräischen Wurzeln', Zeitschrift der Deutschen Morgenländischen Gesellschaft 114: 16-58. 


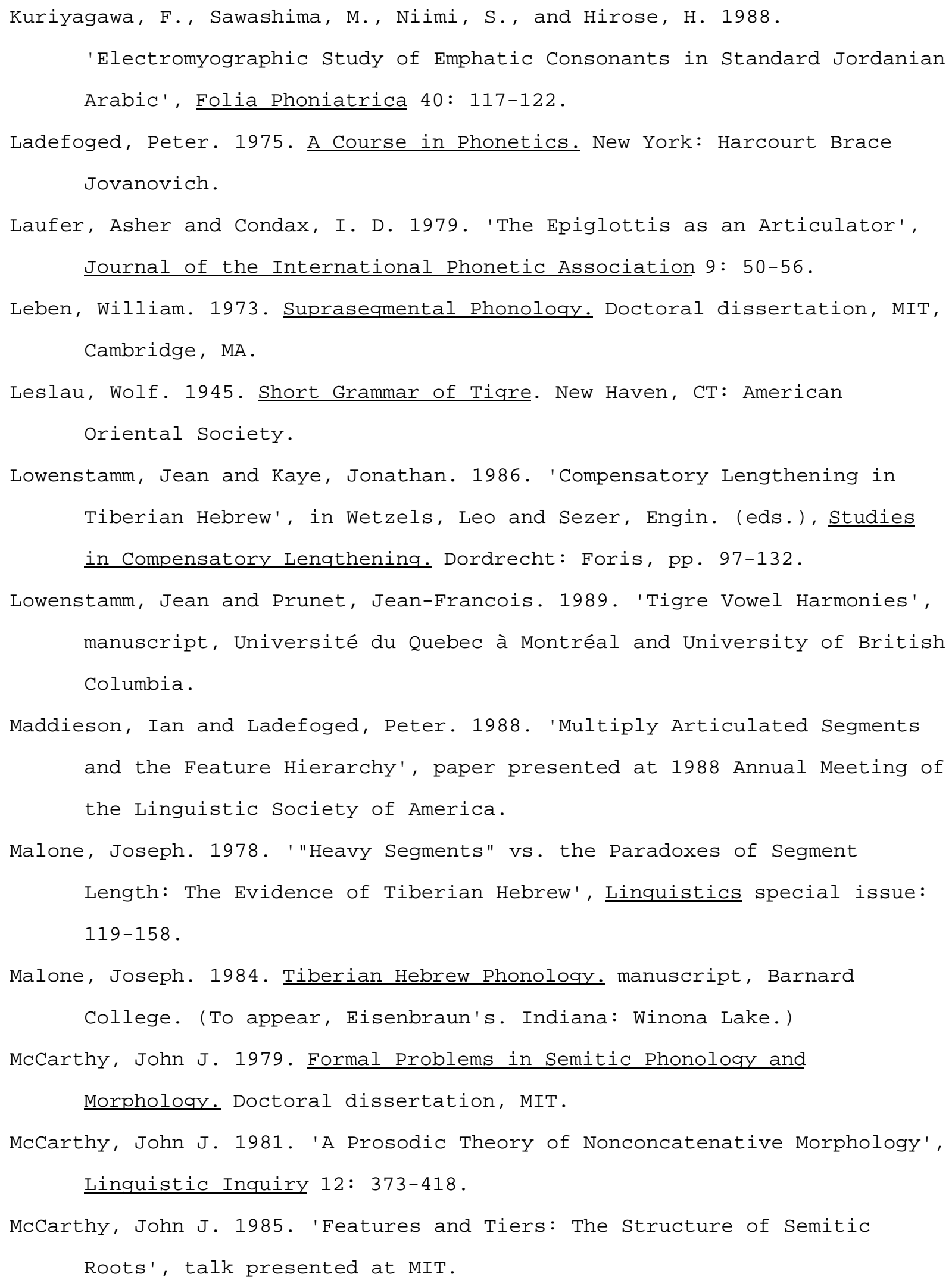


McCarthy, John J. 1986. 'OCP Effects: Gemination and Antigemination', Linguistic Inquiry 17: 207-263.

McCarthy, John J. 1988. 'Feature Geometry and Dependency: A Review', Phonetica 43: 84-108.

McCarthy, John J. 1989. 'Guttural Phonology', ms., University of Massachusetts, Amherst.

McCarthy, John J. 1991a. 'Semitic Gutturals and Distinctive Feature Theory', in Comrie, B. and Eid, M. (eds.), Perspectives on Arabic Linguistics III. Amsterdam: Benjamins. pp. 63-91. [Also appeared (1990) in Dunlap, Elaine and Padgett, Jaye (eds.), UMOP 14. Amherst, MA: Graduate Linguistic Student Association. pp. 29-50.] McCarthy, John J. 1991b. 'The Phonology of Semitic Pharyngeals', ms., University of Massachusetts, Amherst.

McCarthy, John J. Forthcoming. 'Guttural Transparency', ms., University of Massachusetts, Amherst.

Merlingen, W. 1977. Artikulation und Phonematik des H. Vienna: Verlag der wissenschaftlichen Gesellschaften Österreichs.

Mester, R. Armin. 1986. Studies in Tier Structure. Doctoral dissertation, University of Massachusetts, Amherst.

Mester, R. Armin and Itō, Junko. 1989. 'Feature Predictability and Underspecification Palatal Prosody in Japanese Mimetics', Language $65:-$.

Mitchell, T. F. 1960. 'Prominence and Syllabication in Arabic', Bulletin of the School of Oriental and African Studies 23: 369-89.

Mrayati, M. 1987. 'Statistical Studies of Arabic Language Roots', in Descout, Raymond. (ed.), Applied Arabic Linguistics and Signal \& Information Processing. Washington: Hemisphere Publishing.

Odden, David. 1988. 'Dissimilation as Deletion in Chukchi', ms., Ohio State University, Columbus, OH.

Padgett, Jaye. 1991. Stricture in Feature Geometry. Doctoral dissertation, University of Massachusetts, Amherst. 
Palmer, F. R. 1956. '"Openness" in Tigre: A Problem in Prosodic Statement', Bulletin of the School of Oriental and African Studies 18: 561-577.

Palmer, F. R. 1962. The Morphology of the Tigre Noun. London: Oxford University Press.

Penfield, W. and Rasmussen, T. 1950. The Cerebral Cortex of Man. New York: Macmillan.

Perkell, Joseph. 1971. 'Physiology of Speech Production: A Preliminary Study of Two Suggested Revisions of the Features Specifying Vowels', MIT Research Laboratory of Electronics Quarterly Progress Report 102: $123-139$.

Perkell, Joseph. 1980. 'Phonetic Features and the Physiology of Speech Production', in Butterworth, B. (ed.), Language Production 1: Speech and Talk. London and New York: Academic Press.

Prince, Alan. 1975. The Phonology and Morphology of Tiberian Hebrew. Doctoral dissertation, MIT, Cambridge, Mass.

Prochazka, Theodore. 1988. Saudi Arabian Dialects. London: Kegan Paul International.

Prunet, Jean-Francois. 1990. 'The Origin and Interpretation of French Loans in Carrier', International Journal of American Linguistics 56: 484502 .

Raz, Shlomo. 1983. Tigre Grammar and Texts. Afroasiatic Dialects 4, Malibu, California: Undena Publications.

Raz, Shlomo. 1986. 'Vowel Quantity in Tigre', in Goldenberg, Gideon (ed.), Ethiopian Studies, Rotterdam \& Boston: A. A. Balkema.

Ringel, Robert L. 1970 'Oral Region Two-point Discrimination in Normal and Myopathic Subjects', in Bosma, James F. (ed.), Second Symposium on Oral Sensation and Perception. Springfield, Ill.: Charles C. Thomas. pp. 309-321.

Sagey, Elizabeth. 1986. The Representation of Features and Relations in Nonlinear Phonology. Doctoral dissertation, MIT. 
Sasse. H.-J. 1979. 'The Consonant Phonemes of Proto-East-Cushitic (PEC): A First Approximation', Afroasiatic Linguistics 7: 1-67.

Selkirk, E. O. 1988. 'Dependency, Place, and the Notion "Tier"', ms., University of Massachusetts, Amherst.

Selkirk, E. O. 1991. 'Vowel Height Features: Evidence for Privativity and Dependency', paper presented at UQAM, Montréal.

Schein, Barry and Steriade, Donca. 1986. 'On Geminates', Linguistic Inquiry $17: 691-744$.

Shaw, Patricia. 1987. 'Non-conservation of Melodic Structure in Reduplication', in Bosch, A., Need, B., and Schiller, E. (eds.), Papers from the 24 rd Annual Regional Meeting of the Chicago Linguistic Society, Part Two: Parasession on Autosegmental and Metrical Phonology. Chicago: Chicago Linguistic Society. pp. 291306.

Steriade, Donca. 1982. Greek Prosodies and the Nature of Syllabification. Doctoral dissertation, MIT, Cambridge, MA.

Steriade, Donca. 1987. 'Locality Conditions and Feature Geometry', in McDonough, Joyce and Plunkett, Bernadette (eds.), Proceedings of NELS 17, Graduate Linguistic Student Association, University of Massachusetts, Amherst. pp. 595-618.

Stevens, K. S. and House, A. 1963. 'Perturbation of Vowel Articulations by Consonantal Context: An Acoustical Study', Journal of Speech and Hearing Research 6: 111-128.

Trigo, Loren. 1991. 'On Pharynx-Larynx Interactions', Phonology 8: 113-136. Wehr, Hans. 1971. A Dictionary of Modern Written Arabic. Cowan, J. M. (ed.), Ithaca, New York: Spoken Language Services.

Williamson, Kay. 1977. 'Multivalued Features for Consonants', Language 53: $843-871$

Wood, S. 1982. 'X-ray and Model Studies of Vowel Articulation', Lund University, Department of Linguistics, Working Papers 23. 
Yip, Moira. 1989. 'Feature Geometry and Co-occurrence Restrictions', Phonology 6: 349-374.

Yip, Moira. 1991. 'Coronals, Consonant Clusters, and the Coda Condition', in Paradis, Carole and Prunet, Jean-François (eds.), The Special Status of Coronals: Internal and External Evidence. New York: Academic Press.

Younes, Munther A. 1982. Problems in the Seqmental Phonology of Palestinian Arabic. Doctoral dissertation, University of Texas, Austin. 
1. Portions of this paper have been circulated as McCarthy (1989, 1991a, 1991b). Additional related material will appear in McCarthy (forthcoming). During the long gestation and mitosis of this paper I have received helpful comments from Nick Clements, Elan Dresher, Louis Goldstein, Rukayyah Herzallah, Morris Halle, John Kingston, Linda Lombardi, Ian Maddieson, Paul Newman, Jaye Padgett, Janet Pierrehumbert, Ken Stevens, Alison Taub, and Loren Trigo. I am particularly grateful for extensive and detailed comments from Ellen Broselow, Lisa Selkirk, and an anonymous reviewer. Remaining errors are my fault.

2. Evidence from non-Semitic languages is comprehensively reviewed by Elorrieta (1991) within a framework related to the one proposed here.

3. Based on a study of vowel register phenomena, Trigo (1991) concludes that tongue root advancement/retraction and larynx raising/lowering are different features that are phonetically (but apparently not phonologically) independent.

4. I disregard the stopped realization of $\underline{I}$ of Iraqi Arabic, since it is apparently a relatively superficial characteristic with no known phonological consequences.

5. But high F1 alone does not define the class of gutturals. El-Halees (1985) has found that speakers use the relatively higher F1 of true pharyngeals to distinguish them from uvulars, so F1 actually functions perceptually to differentiate among gutturals.

6. There are very substantial problems with the interpretation and use of the Penfield sensory homunculus, but I know of no better alternative.

7. Michael Kenstowicz has directed my attention to Kuriyagawa et al. (1988), an EMG study of the geniohyoid and posterior genioglossus (GGP) during the production of Arabic emphatic consonants (coronals with secondary upper pharynx constriction). The experimental materials contain 
two words with $\underline{\hbar}$ as well. Kuriyagawa et al. find that plain $\underline{s}$ and $\underline{t}$ have activity in the GGP but emphatic $\underline{S}$ and $\underline{T}$ do not. The pharyngeal $\underline{\hbar}$ is like the emphatics in this respect. This might be a slight indication of a motoric connection between the emphatics (which are similar to the uvulars) and the pharyngeals, but there is another explanation. As Ghazeli (1977) notes, plain $\underline{s}$ and $\underline{t}$ in Arabic are considerably fronted (they are dental, with a forward tongue body, enhancing their dissimilarity from $\underline{S}$ and $\underline{T})$, and the GGP activity is consistent with that.

8. The allophonically pharyngealized vowel I has a negative value for the first factor, but its value is much higher than for $\underline{i}$. The vowel $\underset{\text { is }}{ }$ positive for the first factor, but less than the value of $\underline{\mathbf{a}}$, so Hess interprets it as [-radical].

9. The evidence for Place-linked structures at underlying representation in Itô (1986) can equally well be understood as evidence for placeless consonants in coda position, as noted by Yip (1991). This removes the only obvious counterexample to the universality of (7) as a condition on underlying representations.

10. The split between coronal sonorants and coronal obstruents is a very different matter -- it is absolute and it is repeated in unrelated languages. It therefore demands a more principled explanation than (9b), though I do not know of one.

11. I have looked for phonological regularities concerning membership in classes $\underline{a / u}$ or $\underline{a / i}$ in Standard Arabic, but there are none (contra Gorecka 1989). For instance, sorting roots according to the consonants adjacent to the thematic vowel, we get ratios of a/i verbs to a/u verbs ranging from 1.03 (labials) to .93 (coronals) to .62 (dorsals). None differ strikingly from the overall ratio of .82. The a/u versus a/i distinction is, however, largely predictable in many modern dialects (Haddad 1984, Herzallah 1990) 
12. Several penetrating questions from Alicja Gorecka led me to reconsider an earlier version of this analysis. Her account of some of the same data can be located in Gorecka (1989: 98f.).

13. Gesenius-Kautzsch (1910: 78) suggest that $\stackrel{e}{\text { rather than }}$ a is the preferred coloring of schwa after the guttural ?. A search of all initial guttural+schwa sequences in the Pentateuch shows that this is not generally true, though the very high frequency of the single word $\underline{7^{e} l \bar{l} \text { him }}$ 'God' may create this false impression.

14. Systematic exceptions involve adjacent $\underline{y}$, which requires $\underline{i}$, and $\underline{e}$ in forms suffixed with $\underline{-\mathrm{k} \overline{\mathrm{a}}}$. There are perhaps 50 other apparent exceptions scattered through the Bible.

15. Geminate integrity (Steriade 1982, Hayes 1986, Schein and Steriade 1986) blocks epenthesis into geminate gutturals (Al-Mozainy 1981: 187-8): 〔axxas 'he dressed up', \absal 'he made something work', lahiaam 'butcher', naћhaas 'blacksmith'.

16. In this and other Bedouin dialects, certain morphological formations (varying slightly from dialect to dialect) are not affected by postguttural epenthesis. Abboud (1979:471) and Al-Mozainy (1981: 187) have particularly comprehensive lists.

17. Like the gutturals, etymologic $\underline{r}$ degeminates in Hebrew, though there are exceptions. Recall too that etymologic $\underline{r}$ sporadically triggers the pre-guttural lowering rule of section X.3.2. There are several possible explanations for this, none of which directly bear on the issue of gutturals as [pharyngeal].

18. In the earliest attestations of Aramaic, the Proto-Semitic reflex of Arabic $\underline{D}$ is written as $\underline{\text { q }}$ ? ?araq $^{\mathrm{a}}$ 'earth' Jer 10,11. It evidently did not merge with original $\underline{q}$, since the subsequent change to $\underline{I}$ did not affect original q. It may be that the q writing of original $\underline{D}$ was intended for 
the intermediate stage $\underline{\boldsymbol{b}}$, giving the sequence of steps ${ }^{{ }} \underline{\mathrm{D}}>{ }^{\star} \underline{\boldsymbol{B}}>\underline{\boldsymbol{I}}$, with the first step paralleling Ugaritic.

19. There is in any case some reason to think that the sounds called "uvular" are actually somewhat inhomogeneous. Keating (1988: 8) has noted that this label is applied to fairly diverse consonants in different languages, and Elorrieta (1991) and Trigo (1991) have demonstrated that, on phonological grounds, there are at least two types of "uvulars" in some languages (back dorsals (Chomsky and Halle 1968) versus complex pharyngealized dorsals (Cole 1987: 93, McCarthy 1989)).

20. There are some unresolved inconsistencies in the descriptions of Tigre that could prove problematic. Tigre emphatics are actually realized as ejectives, as in other Ethiopian Semitic languages.

A similar example comes from Hoberman's (1985) analysis of the historical phonology of Neo-Aramaic in Northern Iraq. Hoberman reconstructs a stage of this language, called Proto-Azerbaijan-Koy Sanjaq, in which $\underline{?}$ and $\underline{\mathbb{S}}$ were in complementary distribution: $\underline{\mathbb{I}}$ occurs in words containing an emphatic consonant, while $\underline{?}$ occurs in all other words. Compare, for example, reconstructed $\star$ izizla with \{aqla. (For independent reasons, it is difficult to show the same complementarity for $\underline{\hbar}$ and $\underline{h}$. A different phenomenon that requires the same classification comes from Kurdish, a non-Semitic language of northern Iraq in close contact with two branches of Semitic (Arabic and Neo-Aramaic). In Kurdish (Kahn 1976, Hoberman 1989), no word can contain more than one consonant from the set $\{\uparrow, \hbar, q, S, T, Z, \breve{C}, P\}--$ that is, the primary pharyngeals $\underline{S}$ and $\underline{\hbar}$ and the emphatics. Arabic loans like Suhbat 'conversation' or quuTiyya 'box', which contain two [pharyngeal] segments, are restructured as $\underline{s}$ lbhæt and goti in Kurdish. Hoberman analyzes this cooccurrence restriction in essentially the same way as the Arabic phenomena of section X.3.1, but again the analysis makes sense only if the laryngeal consonants are not [pharyngeal]. 
